\title{
The LysR-Type Transcriptional Regulator BsrA (PA2121) Controls Vital Metabolic Pathways in Pseudomonas aeruginosa
}

\author{
Magdalena Modrzejewska, ${ }^{a}$ Adam Kawalek, ${ }^{a}$ (D) Aneta Agnieszka Bartosik ${ }^{a}$
}

alnstitute of Biochemistry and Biophysics, Polish Academy of Sciences, Warsaw, Poland

\begin{abstract}
Pseudomonas aeruginosa, a facultative human pathogen causing nosocomial infections, has complex regulatory systems involving many transcriptional regulators. LTTR (LysR-Type Transcriptional Regulator) family proteins are involved in the regulation of various processes, including stress responses, motility, virulence, and amino acid metabolism. The aim of this study was to characterize the LysR-type protein BsrA (PA2121), previously described as a negative regulator of biofilm formation in $P$. aeruginosa. Genome wide identification of BsrA binding sites using chromatin immunoprecipitation and sequencing analysis revealed 765 BsrA-bound regions in the $P$. aeruginosa PAO1161 genome, including 367 sites in intergenic regions. The motif $\mathrm{T}-\mathrm{N}_{11}-\mathrm{A}$ was identified within sequences bound by BsrA. Transcriptomic analysis showed altered expression of 157 genes in response to BsrA excess; of these, 35 had a BsrA binding site within their promoter regions, suggesting a direct influence of BsrA on the transcription of these genes. BsrA-repressed loci included genes encoding proteins engaged in key metabolic pathways such as the tricarboxylic acid cycle. The panel of loci possibly directly activated by BsrA included genes involved in pilus/fimbria assembly, as well as secretion and transport systems. In addition, DNA pull-down and regulatory analyses showed the involvement of PA2551, PA3398, and PA5189 in regulation of bsrA expression, indicating that this gene is part of an intricate regulatory network. Taken together, these findings reveal the existence of a BsrA regulon, which performs important functions in P. aeruginosa.
\end{abstract}

IMPORTANCE This study shows that BsrA, a LysR-type transcriptional regulator from Pseudomonas aeruginosa, previously identified as a repressor of biofilm synthesis, is part of an intricate global regulatory network. BsrA acts directly and/or indirectly as the repressor and/or activator of genes from vital metabolic pathways (e.g., pyruvate, acetate, and tricarboxylic acid cycle) and is involved in control of transport functions and the formation of surface appendages. Expression of the bsrA gene is increased in the presence of antibiotics, which suggests its induction in response to stress, possibly reflecting the need to redirect metabolism under stressful conditions. This is particularly relevant for the treatment of infections caused by $P$. aeruginosa. In summary, the findings of this study demonstrate that the BsrA regulator performs important roles in carbon metabolism, biofilm formation, and antibiotic resistance in $P$. aeruginosa.

KEYWORDS Pseudomonas aeruginosa, LysR-type transcriptional regulator, LTTR, BsrA regulon, tricarboxylic acid cycle, regulatory network

egulation of transcription is the principal mechanism controlling gene expression and the most economical way for a cell to respond to a rapidly changing environment. One of the largest groups of transcriptional regulators, with representatives in bacteria, archaea, and even eukaryotic organisms (1, 2), is the LysR Type Transcriptional Regulator (LTTR) family (3). Most LTTRs have two conserved and similarly organized functional
Citation Modrzejewska M, Kawalek A, Bartosik AA. 2021. The LysR-type transcriptional regulator BsrA (PA2121) controls vital metabolic pathways in Pseudomonas aeruginosa. mSystems 6:e00015-21. https://doi .org/10.1128/mSystems.00015-21.

Editor Rafael Silva-Rocha, FMRP-USP

Copyright $\odot 2021$ Modrzejewska et al. This is an open-access article distributed under the terms of the Creative Commons Attribution 4.0 International license.

Address correspondence to Aneta Agnieszka Bartosik, anetab2@ibb.waw.pl.

BsrA is a part of an intricate regulatory network, which control metabolic pathways during adaptation to changing environment

Received 5 January 2021

Accepted 16 June 2021

Published 13 July 2021 
domains $(1,4)$. The N-terminal DNA-binding domain (DBD) with a winged helix-turn-helix motif mediates binding to cognate promoter sequences. The C-terminal effector-binding domain (EBD), usually composed of two response subdomains (RD1 and RD2), is involved in ligand recognition and modulation of $\operatorname{DBD}$ activity $(1,3,5)$. The conserved subdomain RD1 is also important for DNA interactions, whereas the more diverse RD2 contains an effector binding site $(1,6)$. LTTRs mediate signal-dependent and signal-independent transcriptional regulation of genes involved in numerous cellular processes, such as oxidative stress response, cell wall shape determination, quorum sensing, regulation of efflux pumps, secretion, motility, nitrogen fixation, virulence, cell division, metabolism, and recognition of environmental stimuli and stresses (1).

The targets of LTTR regulation are often transcribed from a promoter that is very close to and may overlap that of a divergently transcribed regulator gene. In many cases, the LTTR positively regulates the target promoter in an effector-responsive manner, while negatively autoregulating its own promoter in the absence of an inducer (7-11). LTTRs can bind to target promoters in two conformations, depending on the presence of an effector. Ligand binding by the LTTR triggers a conformational change that permits binding to a DNA sequence involved in the regulation of its target gene. LTTRs may act as multimers, most frequently tetramers (12). Studies on several LTTRs have shown that the apoproteins can bind their promoters as tetramers, causing an extended DNase I footprint and a high-angle DNA bend, while the corresponding holoproteins produce a smaller footprint and lower DNA bend angle (1, 5). LTTRs usually bind to a sequence of approximately 50 to $60 \mathrm{bp}$, containing two distinct sites: a recognition-binding site or repression-binding site (RBS), encompassing the sequence $\mathrm{T}^{-} \mathrm{N}_{11^{-}}$A (LTTR box), often located around position -65 relative to the start of transcription, and an activation-binding site (ABS) consisting of the -35 (ABS-35) and -10 (ABS-10) promoter regions $(1,5)$. In the absence of inducer, the LTTR tetramer binds to an RBS, but also with low affinity to the ABS-10 site, causing a bend in the DNA, leading to repression of the target gene by blocking availability of the -35 promoter region (13-15). The bent DNA is relaxed upon effector binding to the LTTR, leading to the formation of an active complex with RNA polymerase to initiate transcription. A "sliding dimer" mechanism was proposed in which activation of the LTTR leads to a shift in the binding site from RBS/ABS-10 to RBS/ABS-35, releasing the -35 box for RNA polymerase recognition and subsequent gene expression $(16,17)$. Concomitantly, the autoregulatory properties of LTTRs are thought to be connected only with the dimeric form of the protein and not bound to the effector. The LTTR might bind to the RBS region of its own gene in a ligand-independent manner to regulate its expression (1).

One of the largest repertoires of LTTRs is encoded in the genome of Pseudomonas aeruginosa, an opportunistic human pathogen causing nosocomial infections, including septicemia, urinary tract infections, pneumonia, and skin and wound infections (18-22). About $10 \%$ of all $P$. aeruginosa genes (usually around 6,000) encode transcription factors. In the first sequenced $P$. aeruginosa genome of reference strain PAO1 (23), 113 genes are annotated as encoding LysR-type transcriptional regulators, but their functions remain largely unknown. $P$. aeruginosa LTTRs with known roles include PA0133 (BauR) (24), PA0739 (SdsB1) (25), PA1413 (26), PA1422 (GbuR) (27), PA1998 (DhcR) (28), PA2076 (OdsR) (29), PA2206 (30), PA2258 (PtxR) (31), PA2432 (BexR) (32), PA2838 (33), PA3225 (34), PA3587 (MetR) (35), PA3630 (GfnR) (36), PA4109 (AmpR) (37), PA4203 (38), PA5437 (PycR) (39), PA1003 (MvfR, also called PqsR) (40-42), PA5344 (OxyR) (43-45), and PA2492 (MexT) $(46,47)$. The membrane-associated multiple virulence factor regulator MvfR was shown to be necessary for $P$. aeruginosa virulence (40). MvfR positively regulates production of the Pseudomonas quinolone signal (PQS), one of three $P$. aeruginosa quorum-sensing systems $(48,49)$, by controlling the pqs $A B C D E$ operon (50), as well as the phnAB genes involved in the biosynthesis of phenazine and anthranilic acid, a precursor of PQS $(50,51)$. Recent reports indicate that MvfR binds to dozens of loci across the $P$. aeruginosa genome at promoter regions and within and outside the coding sequences of genes, recognizing different DNA binding motifs (41, 
42), suggesting its involvement in the regulation of multiple genes. OxyR, another well characterized $P$. aeruginosa LTTR, is involved in the oxidative stress response, acting as a redox sensor (43). OxyR is activated by hydrogen peroxide $\left(\mathrm{H}_{2} \mathrm{O}_{2}\right)$ and protects cells from toxic oxygen derivatives by stimulating the expression of the $\operatorname{kat} A, \operatorname{kat} B$, ahpB, and $a h p C F$ genes encoding catalases and alkyl hydroperoxide reductases $(43,52)$. It was recently shown that OxyR also regulates several other processes such as iron homeostasis, pyocyanin production, and quorum sensing by binding to an AT-rich motif $(44,45,53)$. Another example of a $P$. aeruginosa LTTR with multiple roles is MexT (PA2492), an activator of the mexEF-oprN operon encoding a multidrug efflux pump involved in resistance to quinolones, chloramphenicol, trimethoprim, and imipenem $(46,47,54)$. Except for these few well-studied examples, the majority of LTTRs in this important pathogen remain uncharacterized.

Recently, a putative LTTR PA2121 was shown to negatively affect biofilm synthesis in the $P$. aeruginosa strain PAK and was therefore named biofilm synthesis repressor BsrA (55). It was shown that the bsrA gene is regulated by the small regulatory protein SrpA during phage infection (56). SrpA is a key regulator controlling core cellular processes in $P$. aeruginosa PAK, including biofilm formation, and this factor binds to the motif TATC-N9-GATA identified within the bsrA promoter region.

Here, we analyzed the role of BsrA in P. aeruginosa strain PAO1161, a derivative of PAO1 (57). In contrast to PAK, neither of these strains encodes srpA homologues. Our data indicate that the mode of BsrA action may differ in the strains PAK and PAO1161, because under the conditions tested, BsrA deficiency or overproduction had no influence on biofilm formation in PAO1161. Using RNA sequencing and chromatin immunoprecipitation, we identified a BsrA regulon, which encompasses a gene encoding a key enzyme of the tricarboxylic acid cycle (TCA), a small RNA, as well as genes engaged in different cellular processes, including some that are potentially involved in biofilm production. Using a DNA pull-down assay and regulatory experiments, we show that other LysR-type regulators bind and regulate the bsrA promoter. Thus, BsrA is a part of an intricate regulatory network, that controls metabolic pathways during adaptation to a changing environment.

\section{RESULTS}

Impact of $\boldsymbol{b s} \boldsymbol{A} \boldsymbol{A}$ deficiency or overexpression on bacterial physiology. To analyze the role of BsrA in P. aeruginosa, a PA01161 $\Delta b s r A$ mutant was constructed. This mutant strain did not display any significant differences in growth in Luria-Bertani (LB) or M9 medium, colony morphology, swimming or swarming, compared to the wild type (WT) parental strain PA01161 (see Fig. S1A to C in the supplemental material). In parallel, the effect of bsrA overexpression was tested by linking the gene to an IPTG (isopropyl- $\beta$-Dthiogalactopyranoside)-inducible promoter in plasmid pMEB63 (lacla-tacp-bsrA). No effects of BsrA overproduction on bacterial growth were observed when IPTG concentrations of $\leq 0.25 \mathrm{mM}$ were used (see Fig. S1D), whereas $0.5 \mathrm{mM}$ IPTG reduced the rate of growth significantly compared to cells carrying the empty vector (see Fig. S1D).

Since bsrA was initially identified as a repressor of biofilm synthesis, the formation of biofilms by the strains lacking or overproducing BsrA was examined. The absence of bsrA had no effect on the production of a biofilm by cells grown in either LB or M9 medium (Fig. 1A). Furthermore, the addition of arginine or a subinhibitory concentration of streptomycin to the growth medium, two compounds known to promote biofilm synthesis in $P$. aeruginosa $(58,59)$, resulted in comparable increases in biofilm formation in WT and $\Delta b s r A$ cells (Fig. 1A). Similarly, an excess of BsrA did not affect biofilm formation (Fig. 1B). These data suggested that BsrA may play an auxiliary or strain-specific role in biofilm formation in $P$. aeruginosa.

Identification of BsrA-regulated genes and binding sites for this transcriptional regulator in the $\boldsymbol{P}$. aeruginosa genome. To identify genes that display BsrA-dependent expression we used RNA sequencing analysis (RNA-seq) to characterize the transcriptome of bsrA-overexpressing cells. In addition, we performed chromatin immunoprecipitation and sequencing analysis (ChIP-seq) to identify BsrA binding sites 
A

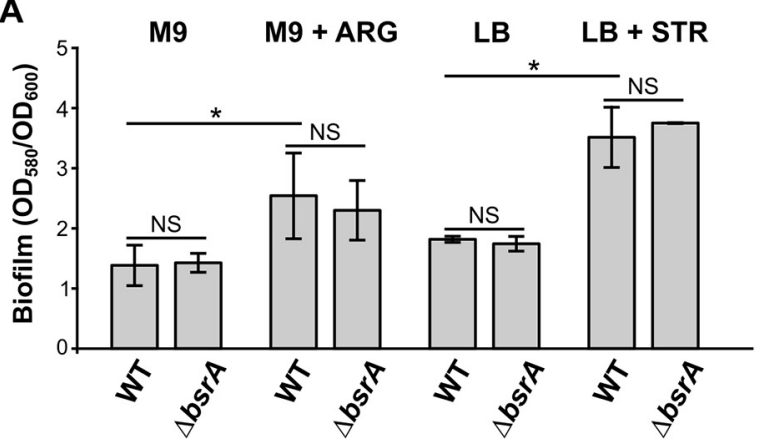

B

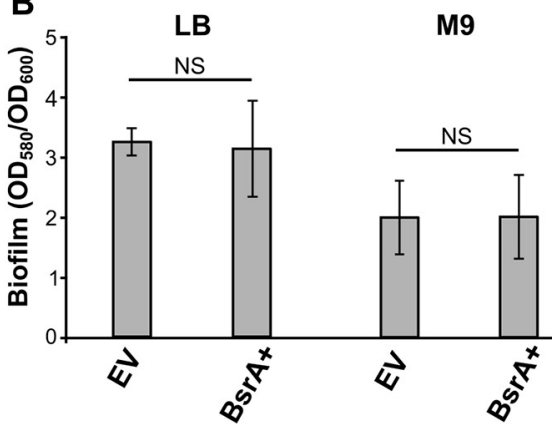

FIG 1 A lack or excess of BsrA does not affect biofilm formation by Pseudomonas aeruginosa PAO1161. (A and B) Biofilm production in static cultures of PA01161 WT and the $\Delta b s r A$ strain grown in M9 medium supplemented with citrate as the carbon source (with or without $20 \mathrm{mM}$ arginine) or in LB medium (with or without $8 \mu \mathrm{g} / \mathrm{ml}$ streptomycin) for $48 \mathrm{~h}(\mathrm{~A})$ and the strain carrying pMEB63 (lacla-tacp-bsrA) overexpressing bsrA (BsrA+) and a control strain carrying empty vector (EV) pAMB9.37 (lacla-tacp), grown in medium supplemented with 0.05 mM IPTG for 72 h (B). OD 600 values were measured and biofilm formation was assessed by staining with crystal violet, followed by measuring the $\mathrm{OD}_{580}$. Data represent the mean $\mathrm{OD}_{580} / \mathrm{OD}_{600}$ ratios \pm the $\mathrm{SD}$ from five biological replicates. ${ }^{*}, P<0.05$ in a two-sided Student $t$ test; NS, not significant $(P>0.05)$.

in the $P$. aeruginosa genome. The rationale behind an analysis of cells with BsrA in excess rather than the $\Delta b s r A$ mutant, was based on the following: (i) the relatively low level of $b s r A$ expression under standard growth conditions (LB or M9 medium; data not shown); (ii) the likelihood that an excess of BsrA might mimic the induced, activated state of the protein; and (iii) the fact that the effector for this LTTR is unknown.

RNA-seq was performed using material isolated from cultures of the strains PA01161 pMEB63 (lacla-tacp-bsrA, hereafter called BsrA+) and PA01161 pAMB9.37 (lacla-tacp, empty vector [EV]) grown in selective LB medium supplemented with 0.05 mM IPTG (see Data Set S1). Comparison of the BsrA + and EV transcriptomes identified 157 loci with altered expression (fold change $[F C] \leq-2$ or $\geq 2$, false discovery rate $[F D R]$ adjusted $P \leq 0.01$ ) (Fig. 2A; see also Data Set S2). The expression of 65 loci was downregulated, whereas 92 loci displayed increased expression. For convenience, we use the $P$. aeruginosa PAO1 gene names throughout the manuscript, although the corresponding PAO1161 gene names are included in all tables. Functional classification of the identified loci, based on PseudoCAP (60), showed that the upregulated genes were mostly involved in protein secretion/export systems, adaptation, and protection, as well as cell wall functions (Fig. 2B; see also Data Set S2). Decreased expression was observed for several genes encoding proteins engaged in carbon compound metabolism and central intermediary metabolism. The most severely downregulated genes were PA3452 (mqoA), encoding a malate:quinone oxidoreductase from the TCA cycle, and $P A 0887$ ( $a \operatorname{cs} A$ ) encoding an acetyl-coenzyme A synthetase $(61,62)$, while the most highly upregulated loci were the mexXY operon, encoding a multidrug efflux RND transporter (63-65), as well as genes encoding type $\mathrm{VI}$ secretion proteins (PA1657 to PA1671) and transporters (PA4192 to PA4195, PA2202, PA2203, PA5024) (see Data Set S2). The altered expression of selected loci in response to BsrA excess was confirmed using RT-qPCR analysis (data not shown).

To identify BsrA binding sites in the $P$. aeruginosa genome, ChIP-seq analysis was performed using an anti-FLAG antibody and $\triangle b s r A$ cells carrying plasmid pMEB99 (tacp-bsrA-flag), grown in selective LB medium supplemented with 0.05 mM IPTG. The addition of a FLAG tag to the $C$ terminus of BsrA did not alter its ability to retard bacterial growth when overproduced (see Fig. S2), indicating that the fusion protein is functional. As a background control for the ChIP procedure, the $\Delta b s r A$ strain carrying plasmid pABB28.1 (tacp-flag) was grown under the same conditions, and samples were processed in parallel. Comparison of BsrA-FLAG ChIP samples with control samples, using a fold enrichment (FE) cutoff value of 2 (Fig. 2C) yielded 765 BsrA-FLAG ChIP-seq peaks (see Data Set S3). The majority of peaks exhibited an FE of between 2 and 4, 
A

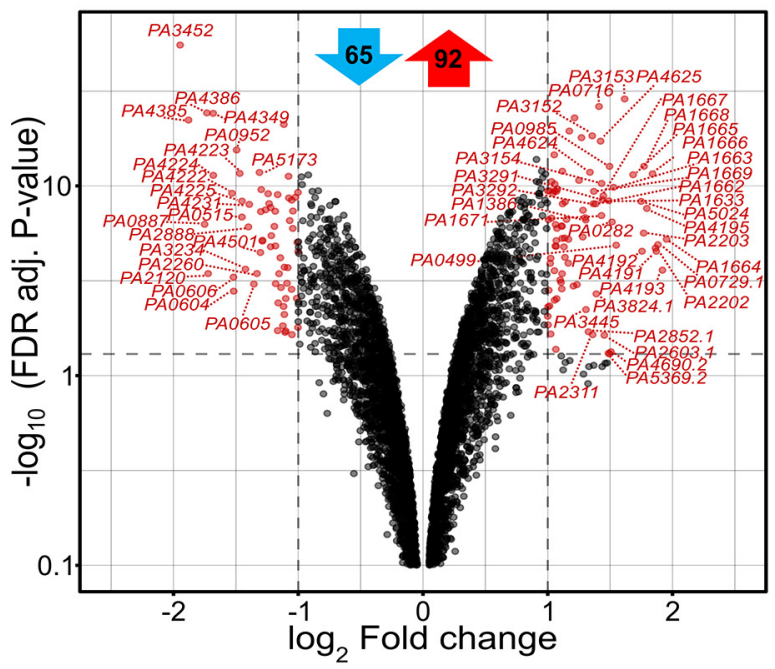

B

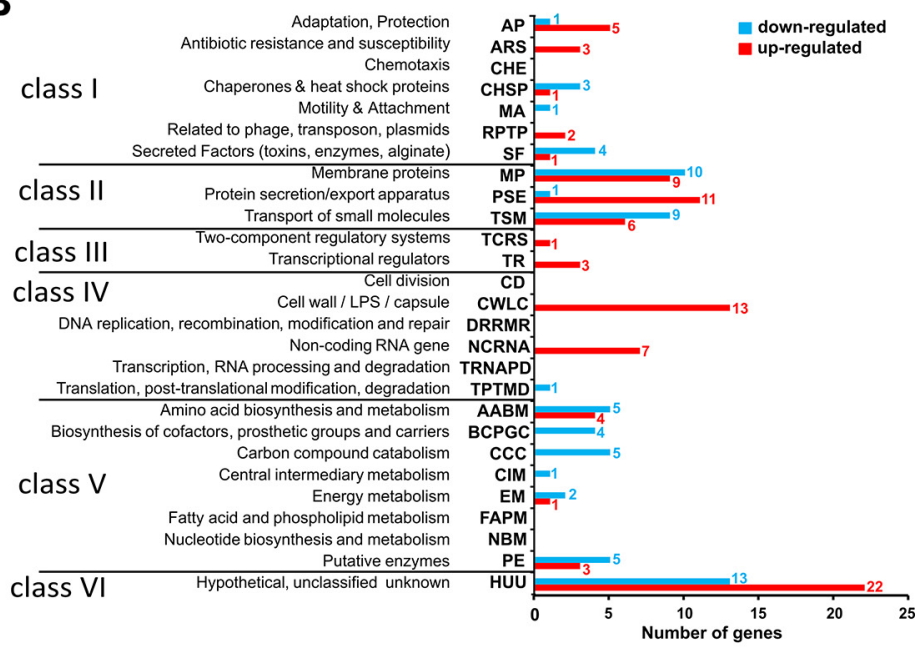

C

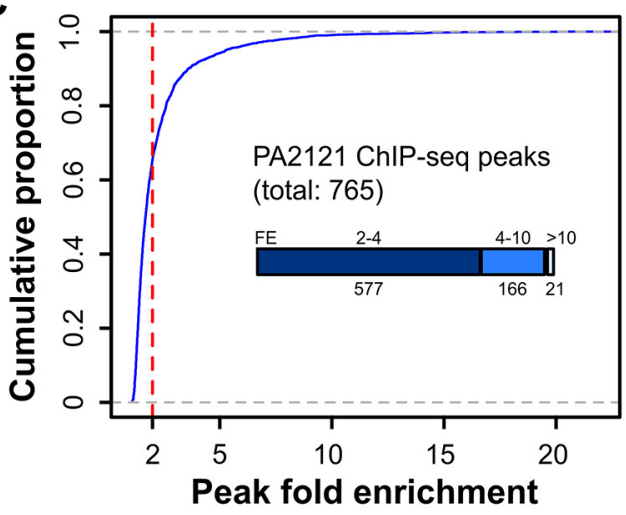

F

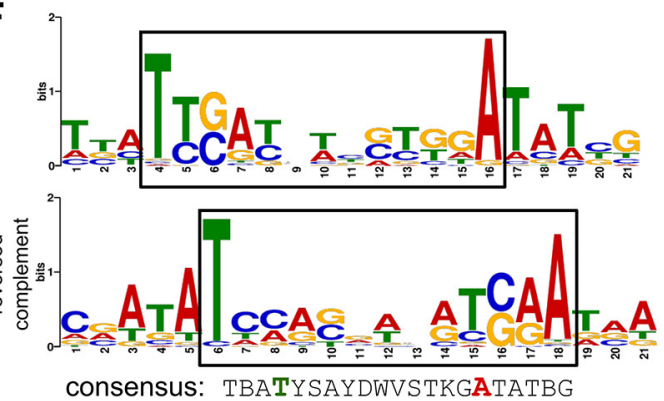

D

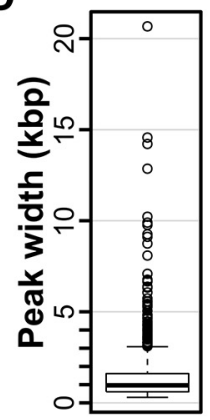

E

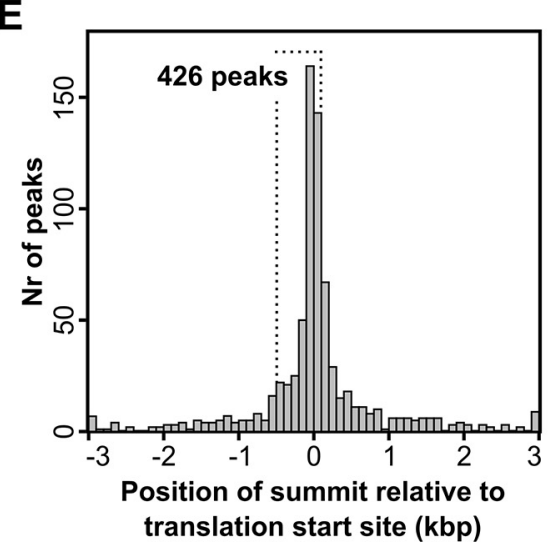

G

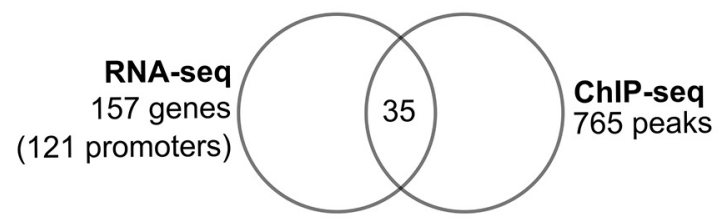

FIG 2 Identification of BsrA-dependent genes and binding sites for this transcriptional regulator in $P$. aeruginosa. Transcriptomes of PAO1161 cells carrying pMEB63 (tacp-bsrA, overexpressing BsrA [BsrA+]) or pAMB9.37 (tacp, empty vector control [EV]), grown under selection in LB medium supplemented with $0.05 \mathrm{mM}$ IPTG were analyzed by RNA-seq. (A) Volcano plot of RNA-seq data comparing the transcriptomes of BsrA+ and EV cells. Differentially expressed genes ( $F C>2$ or $<-2$, and FDR-corrected $P \leq 0.01)$ are indicated in red, and the genes with the most significant changes in expression are named. For clarity, genes with a $P<0.1$ are not shown. The numbers of up- and downregulated loci are presented at the top in red and blue arrows, respectively. (B) Classification of loci with altered expression in response to BsrA excess according to PseudoCAP categories (60). When a gene was assigned to multiple categories, the most informative category was selected (in boldface in Data Set S2). The PseudoCAP categories were additionally grouped into six classes (103, 109). Red and blue bars correspond to the numbers of up- and downregulated genes, respectively. (C) Identification of BsrA binding sites in the $P$. aeruginosa genome. Cells expressing BsrA-FLAG (or the control) were subjected to chromatin immunoprecipitation using anti-FLAG antibodies. Reads obtained by sequencing of the ChIP DNA were mapped onto the PAO1161 genome (57), and peaks were called using MACS2. The chart represents the distribution of fold enrichment (FE) values for the detected peaks. A cutoff value of 2 is indicated by a red line. (D) Width distribution of BsrA ChIP-seq peaks. (E) Distribution of the distance between ChIP-seq peak summits and the nearest start codon. Bin width is 100 nucleotides. Peaks with distances of $>3 \mathrm{kbp}$ are grouped together in boundary bins. (F) Sequence logo of the BsrA binding motif obtained by MEME (66). The reverse complement of this logo and a proposed consensus sequence are presented below. $\mathrm{B}=\mathrm{C}$ or $\mathrm{G}$ or $\mathrm{T} ; \mathrm{Y}=\mathrm{C}$ or $\mathrm{T} ; \mathrm{S}=\mathrm{G}$ or $\mathrm{C} ; \mathrm{D}=\mathrm{A}$ or $\mathrm{G}$ or $\mathrm{T} ; \mathrm{W}=\mathrm{A}$ or $\mathrm{T} ; \mathrm{K}=\mathrm{G}$ or $\mathrm{T}$. The $\mathrm{LTTR}$ box $\left(\mathrm{T}-\mathrm{N}_{11}-\mathrm{A}\right)$ is framed in black. (G) Overlap between RNA-seq and ChIP-seq results. A gene was classified as likely to be directly regulated by BsrA if the ChIPseq peak summit was located in the region -500 to +100 from its start codon (or the start codon of the corresponding operon). 
although 166 had FE values of 4 to 10, and 21 had an FE of $>10$ (Fig. 2C). The mean width of ChIP-seq peaks was $<1,000$ (twice the length of the DNA fragments used for ChIP), indicating BsrA binding to single or closely spaced binding site(s) (Fig. 2D). The summits of 367 peaks (48\%) mapped to intergenic regions (see Data Set S3). A similar analysis of peak summit positions relative to the start codons of PAO1161 open reading frames (or the first genes in operons) showed that 426 peaks were located in the -500 to +100 regions, which suggests that the expression of these loci could be regulated by BsrA (Fig. 2E).

An extensive search for nucleotide motifs shared by sites bound by BsrA using MEME (66) showed the presence of a consensus sequence resembling the T- $\mathrm{N}_{11}-\mathrm{A}$ motif (LTTR box) (Fig. 2F) proposed as the binding site of other LTTRs $(1,67,68)$. These data indicated that BsrA has multiple binding sites in the $P$. aeruginosa genome, which suggests that this factor may function as a modulator of gene expression in regulatory networks.

Genes under the direct control of BsrA. Interestingly, 35 of the 157 genes showing altered expression in response to a BsrA excess possessed a binding site for this transcriptional regulator within their promoter regions (Fig. $2 \mathrm{G}$ and Table 1). In addition, 55 BsrA peaks detected in coding regions were in the vicinity of genes that showed changes in expression level (FC $>1.5$ or $<-1.5$ ) in RNA-seq analysis (see Data Set S3), but the mechanism by which BsrA could influence their expression requires further studies.

Our analysis confirmed that BsrA might bind within the region preceding its own coding sequence (Fig. 3A). A BsrA binding site was also detected in the putative promoter of PA3452 (mqoA): the gene showing the most severe downregulation in the RNA-seq analysis ( $F C=-3.86$ ) (Fig. $3 B$ ). Among the genes that might be directly regulated by BsrA, PA1112.1, encoding a small noncoding RNA of unknown function (69), had a peak with the greatest fold enrichment (12.7) in the region preceding the structural gene (Fig. 3C).

To confirm the interactions of BsrA with putative promoters of these genes, we performed electrophoretic mobility shift assays (EMSAs) using purified $\mathrm{His}_{6}$-BsrA and DNA fragments corresponding to the putative promoter regions of $b s r A, P A 3452$, and PA1112.1. Shifts of the promoter fragment DNA bands, but not of a nonspecific competitor DNA, were observed, indicating that $\mathrm{His}_{6}$-BsrA binds to these regions in vitro (Fig. $3 \mathrm{D}$ to F). To verify the importance of the LTTR box sequences in DNA binding by BsrA, version of the PA1112.1 promoter fragment lacking the $\mathrm{T}-\mathrm{N}_{11}-\mathrm{A}$ motif was tested in an EMSA. No BsrA binding to this shortened fragment (232 bp instead of $303 \mathrm{bp}$ ) could be detected (Fig. 3G).

To further examine the influence of BsrA on the expression of the three aforementioned genes, their promoter regions were cloned upstream of a promoter-less $x y / E$ gene in the vector PPTOI. The $b s r A$ and PA1112.1 promoters were active in the heterologous host Escherichia coli DH5 $\alpha$, whereas no activity was observed for PA3452p (Fig. $3 \mathrm{H}$ and I and data not shown). Expression of BsrA in cells carrying plasmids with bsrAp-xylE or PA1112.1p-xylE resulted in significantly reduced XylE activity in the corresponding cell extracts (Fig. $3 \mathrm{H}$ and I). Moreover, RT-qPCR analysis of PA3452 (mqoA) and PA1112.1 transcript levels in bsrA-deficient cells showed increased expression of these two genes relative to WT cells, which supported the repressive effect of BsrA on the transcription of these genes (Fig. $3 \mathrm{~J}$ and $\mathrm{K}$ ).

These data confirmed that BsrA binds to DNA fragments identified in ChIP-seq analysis and may regulate the activity of target promoters to influence gene expression. In addition, the T- $\mathrm{N}_{11}$-A nucleotide sequence, known as the LTTR box, present in the binding sites of most LTTRs $(1,67)$, is recognized by BsrA.

Modulation of different cellular processes by BsrA. The RNA-seq results suggested that BsrA is engaged in modulating the activity of proteins mediating the conversion of malate to oxaloacetate in the TCA cycle by repressing the expression of the PA3452 (mqoA) and PA4640 (mqoB) genes (see Data Set S1). This is likely to influence subsequent steps of the cycle, e.g., the availability of oxaloacetate, its conversion to citrate using acetyl coenzyme A (acetyl-CoA) or the levels of acetyl-CoA generated via the pyruvate shunt (Fig. 4A). In addition, several genes that are putatively involved in the acetate transport (PA3233 and PA3234) (70) and acetate pathways (acsA [PA1562], acsB [PA1787], and exaC 


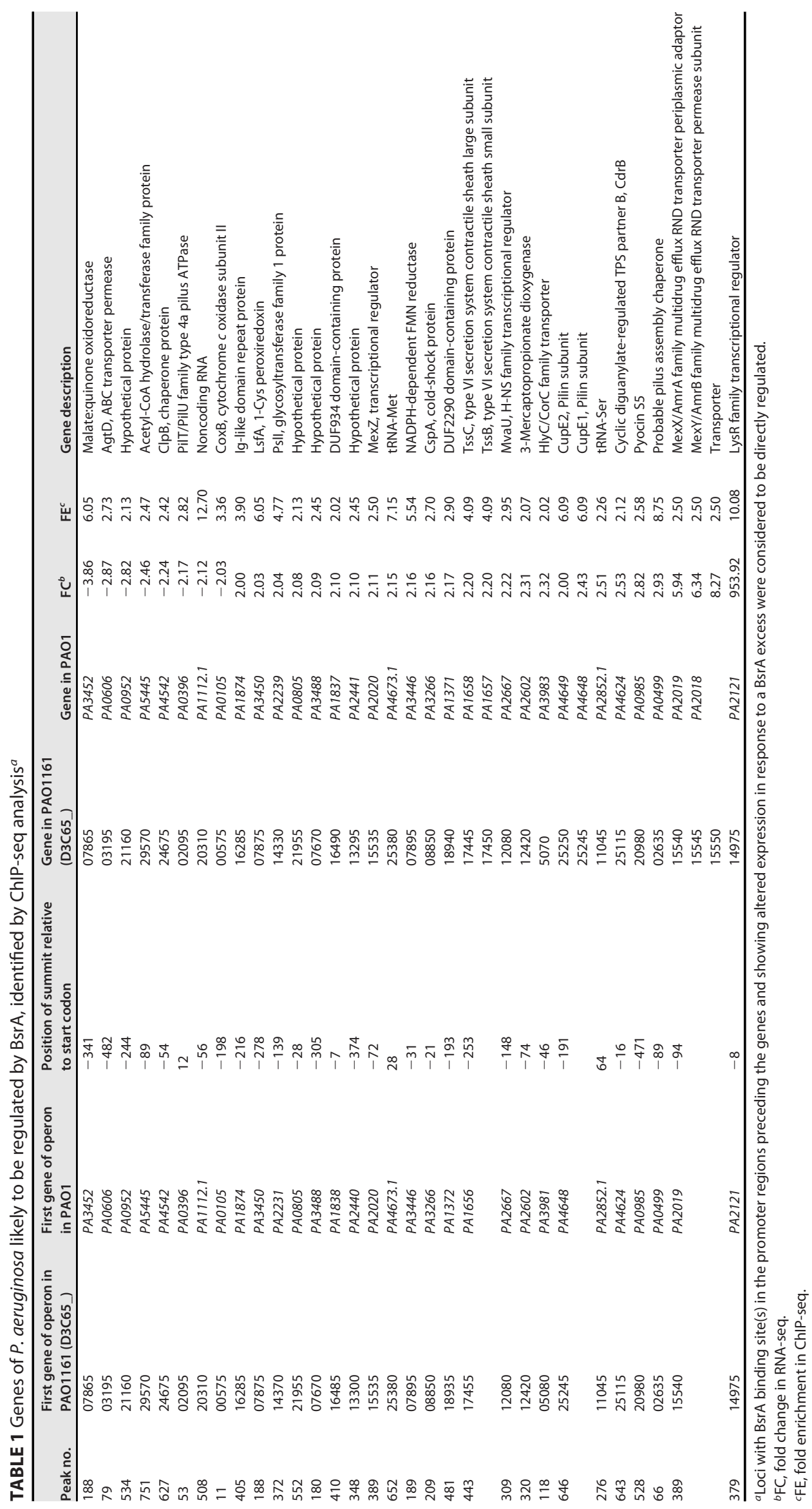


BsrA ChIP $\square$ control

A

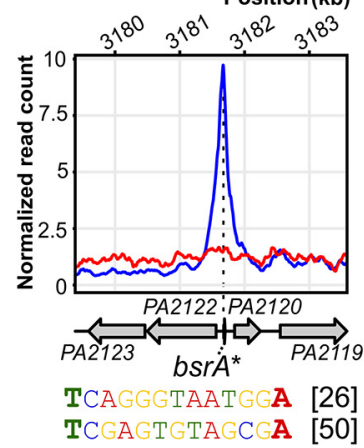

B

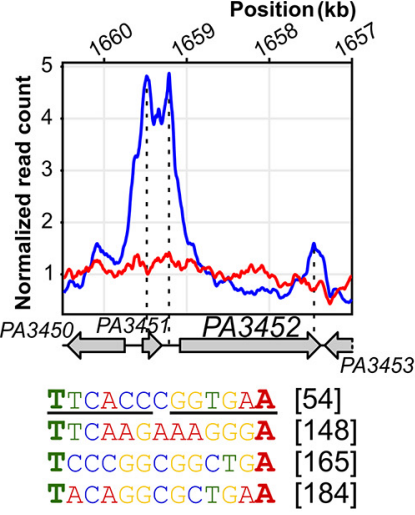

C

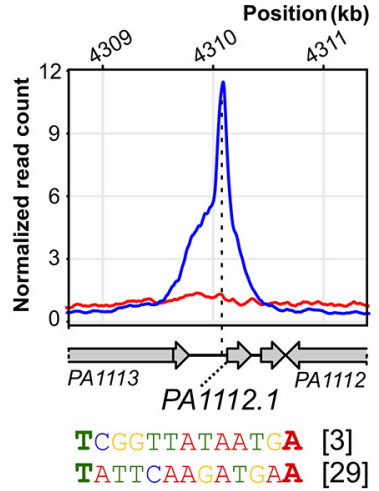

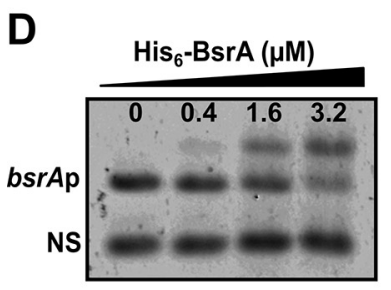

H

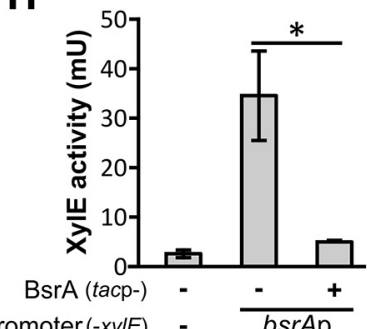

E

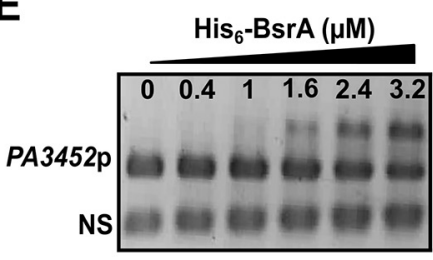

I

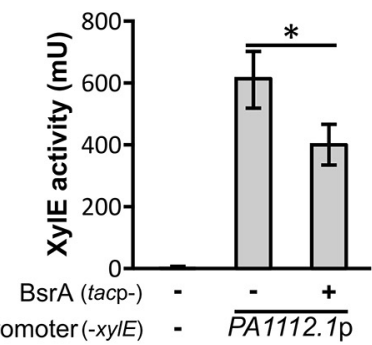

F

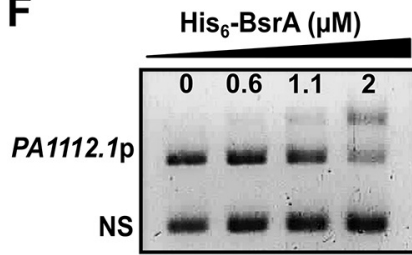

G

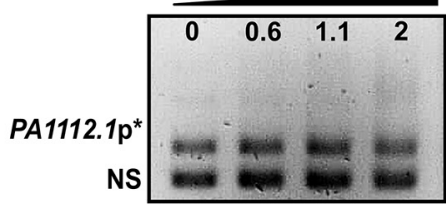

J

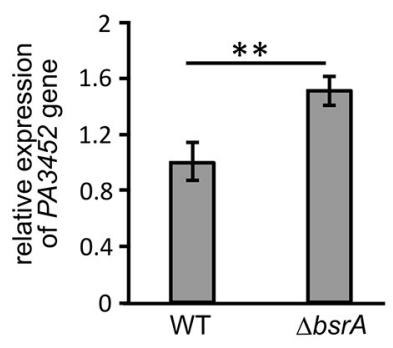

K

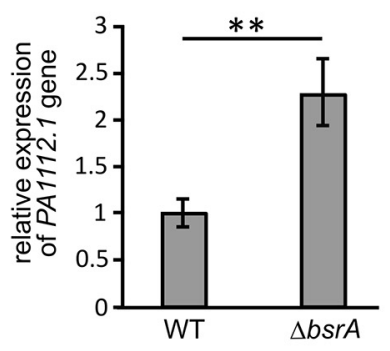

FIG 3 Direct regulation of target promoters by BsrA binding. (A to C) ChIP-seq signal over the regions preceding the bsrA (A), PA3452 (B), and PA1112.1 (C) genes. The plots show normalized read counts, averaged for ChIP replicates, for the indicated positions in the PAO1161 (CP032126.1) genome. Genes are represented as arrows and the names of the PAO1 orthologues are shown for clarity. Sequences within the analyzed promoter fragments that correspond to the $\mathrm{T}-\mathrm{N}_{11}-\mathrm{A}$ motif are presented below the plots, including their positions relative to the start codon (underlined sequences indicate a pseudopalindrome). (D to G) EMSA analysis of $\mathrm{His}_{6}$-BsrA binding to regions preceding bsrA (D), PA3452 (E), PA1112.1 (F), and truncated PA1112.1p (lacking 71 bp containing the $\mathrm{T}-\mathrm{N}_{11}-\mathrm{A}$ motif) $(\mathrm{G})$. DNA fragments $(0.1 \mu \mathrm{M})$ were incubated with the indicated amounts of His $-\mathrm{Bss}^{\mathrm{A}} \mathrm{A}$, and complexes were separated by electrophoresis on $1.5 \%$ (D to $F$ ) or $2.5 \%(G)$ agarose gels subsequently stained with ethidium bromide. A 199 -bp fragment of empty vector pCM132 (labeled as NS) was used as a control of binding specificity and a competitor DNA. (H and I) XylE activity in E. coli DH5 $\alpha$ double transformants carrying pMEB190 (bsrAp-xyIE) (H) or pMEB232 (PA1112.1p-xyIE) (I) plus pMEB63 (lacla-tacp-bsrA) for BsrA overproduction (+) or control plasmid pAMB9.37 (-). Strains were grown in selective LB medium. Data for cells carrying the promoter-less pPTOI (-xylE) and pAMB9.37 are shown as background controls. The data represent the means \pm the standard deviations from three biological replicates. ${ }^{*}, P<0.05$ in a Student two-tailed $t$ test. ( $\mathrm{J}$ and $\mathrm{K}$ ) Relative expression (RT-qPCR) of PA3452 (J) and PA1112.1 (K) in WT and $\Delta$ bsrA cells from exponentially growing cultures $\left(\mathrm{OD}_{600} 0.2\right)$ normalized to the reference gene rpsL. ${ }^{* *}$, $P<0.01$ in a Student two-sided $t$ test assuming equal variance.

[PA1984]), encoding probable succinyl-CoA/acetate CoA-transferase (PA5445) (71), also showed reduced expression ( $F C$ between -2 and -1.5 ) in response to BsrA (Fig. 4A; see also Table S1) $(72,73)$, suggesting the involvement of this LTTR in controlling acetate metabolism. We cultured the WT and $\Delta b s r A$ strains in minimal medium supplemented with citrate or acetate as the sole carbon source, but no visible effects on the kinetics of growth were observed (see Fig. S1B). To test the effect of BsrA on acetate metabolism, the two strains were also cultured in medium containing a subinhibitory concentration of kanamycin, following the report of Meylan and coworkers, showing the effect of central carbon metabolite stimulation on aminoglycoside sensitivity in $P$. aeruginosa (74). The propagation of cells from overnight cultures in M9 medium containing $50 \mu \mathrm{g} / \mathrm{ml}$ kanamycin and acetate as the sole carbon source resulted in an increase in CFU/ml (relative to the starting point) of the $\Delta b s r A$ mutant, while the CFU/ml value of the WT strain was not significantly changed (Fig. 4B). This effect was not observed when pyruvate and fumarate (compounds 
A

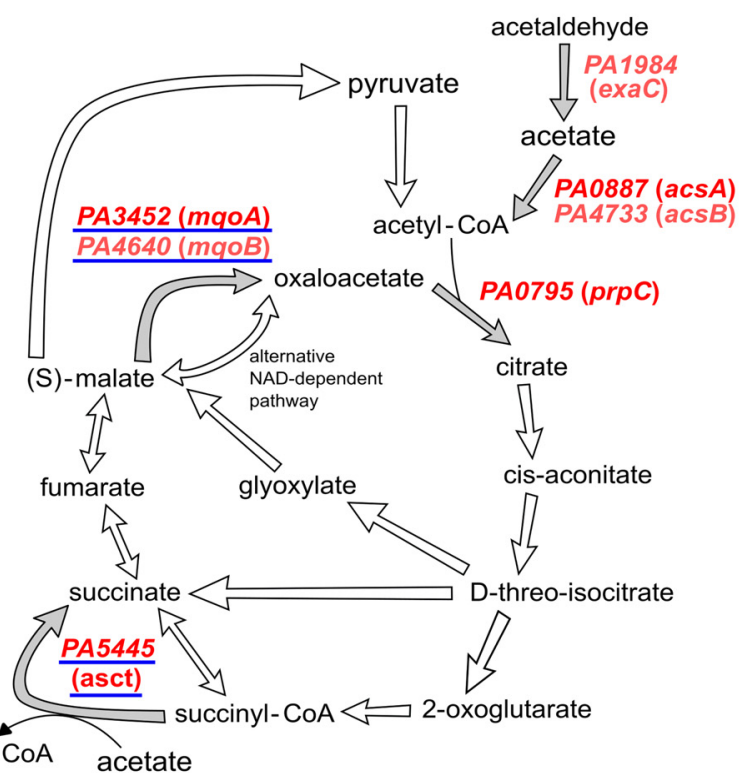

C

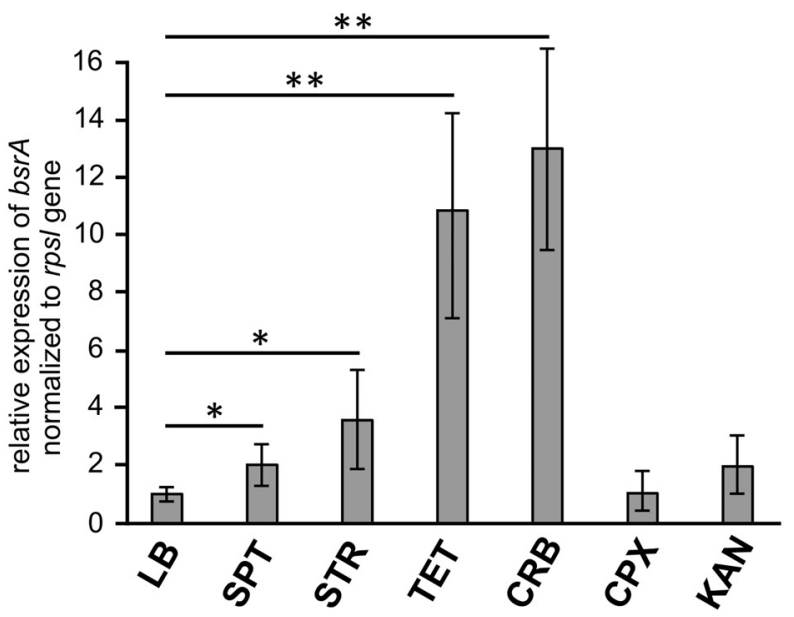

B
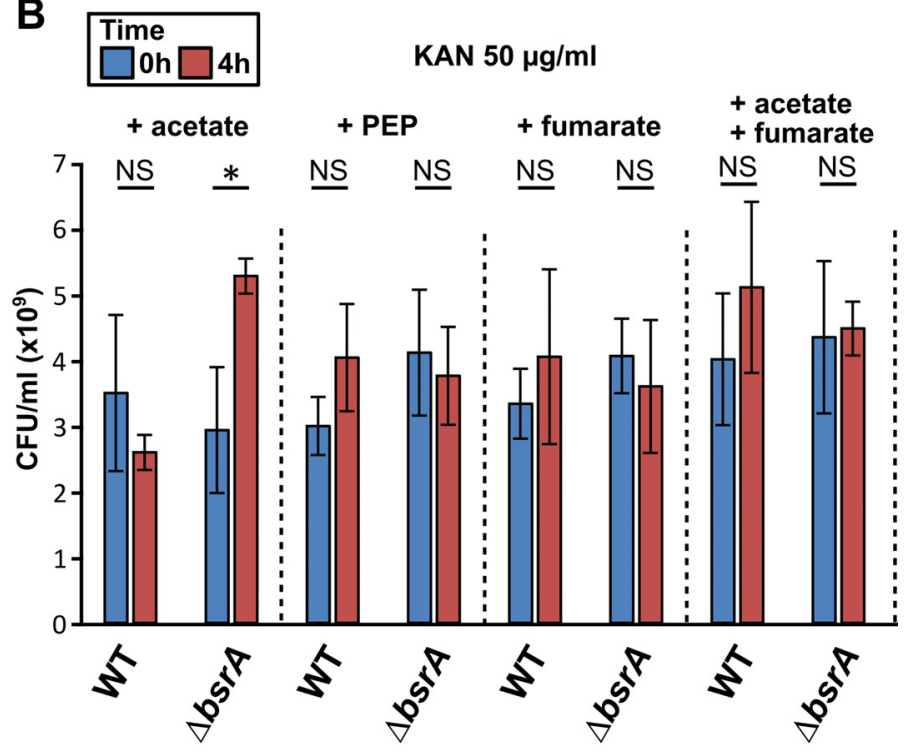

D

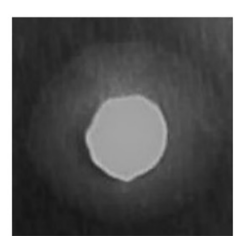

EV

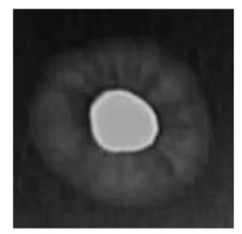

BsrA+
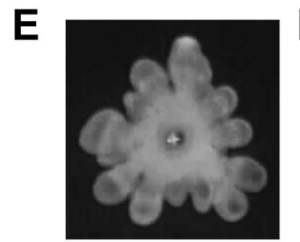

EV

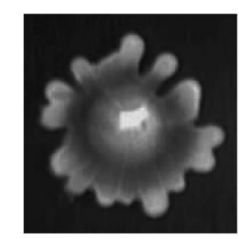

BsrA+

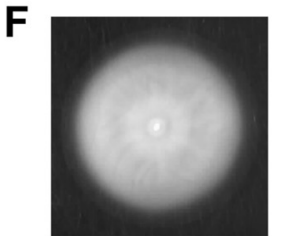

EV

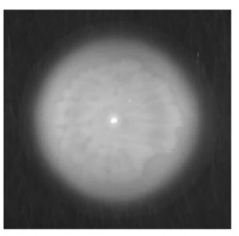

BsrA+

FIG 4 BsrA participates in the regulation of different processes in P. aeruginosa PAO1161. (A) Scheme of the TCA cycle (71, 73, 82, 96). Genes identified as affected by BsrA overproduction are indicated in red (dark red: $\mathrm{FC}<-2$ ). Genes with BsrA binding sites in their promoters are underlined. (B) Viable cell density (CFU/ml) of overnight cultures of PAO1161 and the $\Delta b s r A$ mutant grown in M9 medium with kanamycin (50 $\mu \mathrm{g} / \mathrm{ml}$ ) and sodium acetate, phosphoenolpyruvate (PEP) or fumarate added as the sole carbon source, in amounts adjusted to maintain a total carbon concentration of $60 \mathrm{mM}$. ${ }^{*}, P<0.05$ in a Student $t$ test assuming equal variance. (C) Relative expression of bsrA in WT PAO1161 cells cultured in LB medium without antibiotic (LB) and with different classes of antibiotic added at subinhibitory concentrations: spectinomycin, $128 \mu \mathrm{g} / \mathrm{ml}$ (SPT); streptomycin, $4 \mu \mathrm{g} / \mathrm{ml}$ (STR); tetracycline, $4 \mu \mathrm{g} / \mathrm{ml}$ (TET); carbenicillin, $32 \mu \mathrm{g} / \mathrm{ml}$ (CRB); ciprofloxacin, $0.06 \mu \mathrm{g} / \mathrm{ml}(\mathrm{CPX})$; and kanamycin, $10 \mu \mathrm{g} / \mathrm{ml}$ (KAN). ${ }^{*}$ and ${ }^{* *}, P<0.05$ and $P<0.01$, respectively, in a Student twosided $t$ test assuming equal variance. (D to F) Twitching (D), swarming (E), and swimming (F) motility of strain PAO1161 carrying pMEB63 (overexpressing bsrA, $\mathrm{BsrA}+$ ) or empty vector pAMB9.37 (control, EV) treated with $0.05 \mathrm{mM}$ IPTG.

from different parts of the TCA cycle) or acetate plus fumarate were used as the carbon source(s). Thus, the $P$. aeruginosa $\Delta b s r A$ mutant exhibited higher survival and/or fitness than the WT strain in the presence of kanamycin when grown in minimal medium supplemented with acetate as the sole carbon source, which confirmed the influence of BsrA on acetate metabolism.

To test the effect of various antibiotics on bsrA expression, we performed RT-qPCR using RNA isolated from PAO1161 cultures grown in medium supplemented with subinhibitory concentrations of different antibiotics. This analysis showed no significant difference in bsrA expression upon the addition of kanamycin or ciprofloxacin compared to a negative control culture (Fig. 4C). Interestingly, the expression of bsrA was significantly increased in response to spectinomycin, streptomycin, tetracycline, and carbenicillin (Fig. 4C), which indicates that bsrA is induced in response to specific antibiotics. 
Our RNA-seq and ChIP-seq results also indicated increased expression of genes involved in fimbria assembly (e.g., PA0499 and PA4648 to PA4653) in response to BsrA in excess. PA0499 is a periplasmic protein predicted to act as a chaperone assisting the assembly of appendages on the surface of the bacterium (75). PA4648 is the first gene of the six-component cupE cluster encoding a so-called chaperone-usher pathway, the activation of which leads to the production and assembly of CupE fimbriae on the cell surface (76). These fimbriae are known to play a crucial role in biofilm development by $P$. aeruginosa and the cupE operon is specifically expressed in biofilm-forming cells (76). Since biofilm formation was unaffected in both the $\triangle b s r A$ and BsrA+ strains (Fig. 1), we checked whether $b s r A$ overexpression had any effect on swimming, twitching or swarming motilities (77-79). BsrA + cells showed differences in twitching (involves pili) and swarming, as demonstrated by the presence of clear radiating motility zones ("lines") spreading from the center of bacterial colonies, that were not observed in the control strain. This may reflect possible changes in radial expansion of the colony, which could be related to enhanced appendage production in BsrA+ cells (Fig. 4D and E). No effect on swimming was observed (Fig. 4F), indicating that BsrA overproduction does not have a general negative effect on the motility of cells grown on plates. Thus, BsrA appears to be involved in the regulation of swarming and twitching motilities, and possibly attachment to surfaces, the first stage in biofilm formation.

Taken together, these results demonstrated the participation of BsrA in a number of diverse cellular processes including the modulation of cellular metabolism in response to growth conditions and the control of appendage formation leading to altered motility of $P$. aeruginosa cells.

BsrA is under the control of other transcriptional regulators in $P$. aeruginosa. The findings of a previous study (55) and our data showed that the expression of bsrA is subject to autoregulation. To identify other proteins that can modulate $b s r A$ transcription and in consequence the level of BsrA, we used a bsrA promoter fragment as bait in a DNA pull-down assay with $P$. aeruginosa PAO1161 cell extracts. The proteins bound to $b s r A p$ were then characterized by mass spectrometry analysis. Altogether, 39 proteins were identified as being able to bind to bsrAp, but not to a control DNA fragment (see Data Set S4). Importantly, BsrA was identified among the proteins with the highest scores, providing a positive control for this approach and confirming the autoregulatory properties of the protein. Six other proteins were identified with high scores for binding to $b s r A p$ in two independently tested samples (eluates): PA2551, PA3587 (MetR), PA4902, PA4462 (RpoN), PA5189, and PA3398. Interestingly, five of these proteins are classified as LysR family transcriptional regulators, whereas PA4462 (RpoN) is a $\sigma^{54}$ factor interacting with RNA polymerase (80). It is known that $\sigma^{54}$ factors direct RNAP to conserved -12 (TGC) and -24 (GG) elements, and similar regions (TGA at position -12 and GG at position -24) are present in the bsrAp.

To determine whether the proteins identified in pull-down analysis can indeed affect the activity of the bsrA promoter, the PA2551, PA3398, PA3587, PA4902, and PA5189 genes were cloned under the control of tacp in vector pAMB9.37 and expressed in cells carrying plasmid pMEB190 (bsrAp-xyIE). Measurements of XylE activity in cell extracts of the double transformants showed that the expression of PA3587 and PA4902 did not significantly influence $b s r A p$ activity under the tested conditions (Fig. 5A). Notably expression of PA2551, PA3398, or PA5189 resulted in major decreases in XylE activity, suggesting that these proteins act directly as repressors of the bsrA gene. Interestingly, ChIP-seq analysis revealed strong binding of BsrA upstream of the PA2551, PA3398, and PA5189 genes (Fig. 5B) but not PA3587 or PA4902 (data not shown).

These results showed that BsrA is part of an intricate regulatory network involving mutual regulation between BsrA and other LysR-type transcription factors.

\section{DISCUSSION}

In this study, we performed a functional analysis of the LysR-type transcriptional regulator BsrA (PA2121) from $P$. aeruginosa, previously described as a repressor of biofilm synthesis (55). 
A

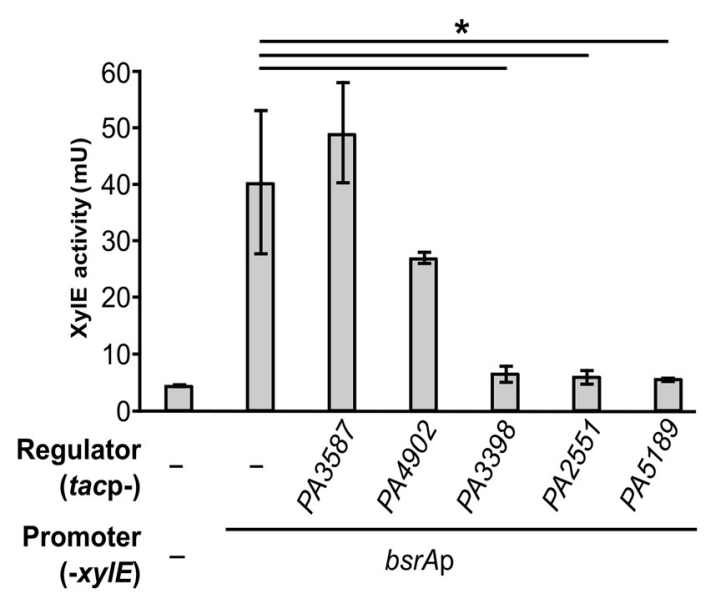

B $=$ BsrA ChIP $\square$ control
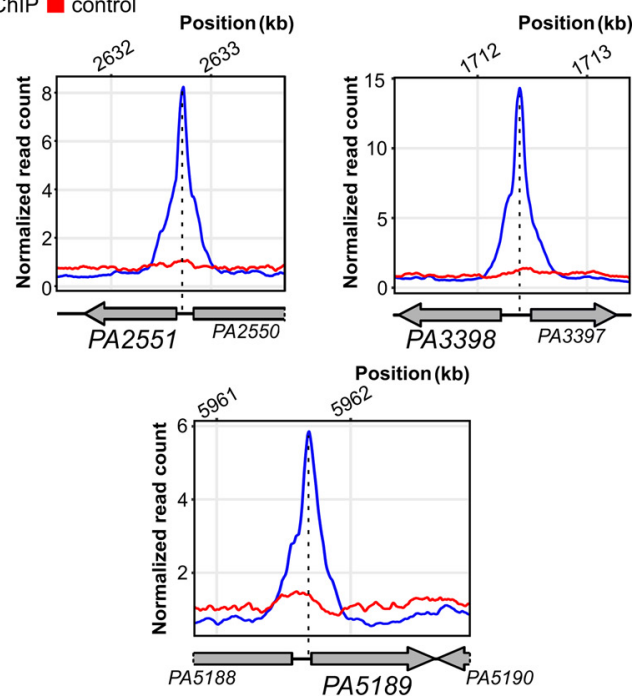

FIG 5 Transcriptional regulators PA2551, PA3398, and PA5189 control expression of bsrA. (A) XylE activity in double transformants of E. coli DH5 $\alpha$ carrying promoter-less pPTOI or pMEB190 (bsrAp-xylE) plus vectors expressing the indicated genes under tac promoter control. Cells were grown in selective LB supplemented with $0.05 \mathrm{mM}$ IPTG. Data represent the means \pm the standard deviations from three biological replicates. ${ }^{*}, P<0.05$ in a Student paired two-tailed $t$ test. (B) ChIP-seq signals over regions preceding the PA2551, $P A 3398$, and PA5189 genes encoding regulators repressing bsrA expression. The plots show normalized read counts, averaged for replicates, for the indicated positions in the PAO1161 (CP032126.1) genome.

Transcriptional analysis of a strain overproducing BsrA revealed the greatest changes in gene expression for loci encoding enzymes engaged in carbon metabolism (mainly downregulated) and for loci predicted or known to be involved in processes connected with transport, biofilm, and type VI secretion systems (upregulated). In a $P$. aeruginosa PAK mutant with disrupted $b s r A$, increased biofilm synthesis was observed (55), while the PAO1161 $\triangle b s r A$ mutant constructed in this study did not show significant changes in biofilm formation (Fig. 1). This difference could be related to the presence of the SrpA protein in the PAK strain, which is not encoded in the genome of PAO1161 (or PAO1). Among its other functions, SrpA directly regulates expression of the $b s r A$ gene by binding to its promoter (56). Our data suggested that another mechanism is responsible for regulating biofilm production, possibly involving BsrA-mediated activation of genes such as PA0499 or PA4648, that have been connected with the formation of biofilms $(75,76)$. The generation of biofilm structures is strictly linked to metabolic activity, which is inhibited in the cells of the mature biofilm matrix but increased during early biofilm development (81). The role of BsrA in biofilm formation might be related to the modulation of these processes. The relationship between SrpA and BsrA in biofilm formation requires further study.

Our data suggested that BsrA is involved in the repression of metabolic functions by direct or indirect downregulation of genes engaged in pyruvate metabolism and the TCA cycle (Fig. 4A and 6). The most highly repressed gene, directly controlled by BsrA, is mqoA (PA3452) encoding a putative malate:quinone oxidoreductase (MQO), a FAD-dependent enzyme involved in the conversion of malate to oxaloacetate. The gene encoding the second $P$. aeruginosa MQO, mqoB (PA4640), was also subject to BsrA-mediated regulation, although to a lesser extent. The presence of $m q \circ B$ is necessary for the growth of cells on acetate and ethanol as sole carbon sources (82). Under these conditions, one of the primary functions of MQOs is to replenish the oxaloacetate pool in the TCA cycle to allow further assimilation of acetyl-CoA and permit TCA operation to provide intermediates for biosynthetic processes and respiration (82). Both MQOs are produced by cells grown under standard aerobic conditions, but the levels of $M q o B$ are higher than those of $\operatorname{MqoA}(33,73,82)$. The precise role of MqoA in $P$. aeruginosa awaits elucidation. Bacterial MQOs have previously been characterized in 


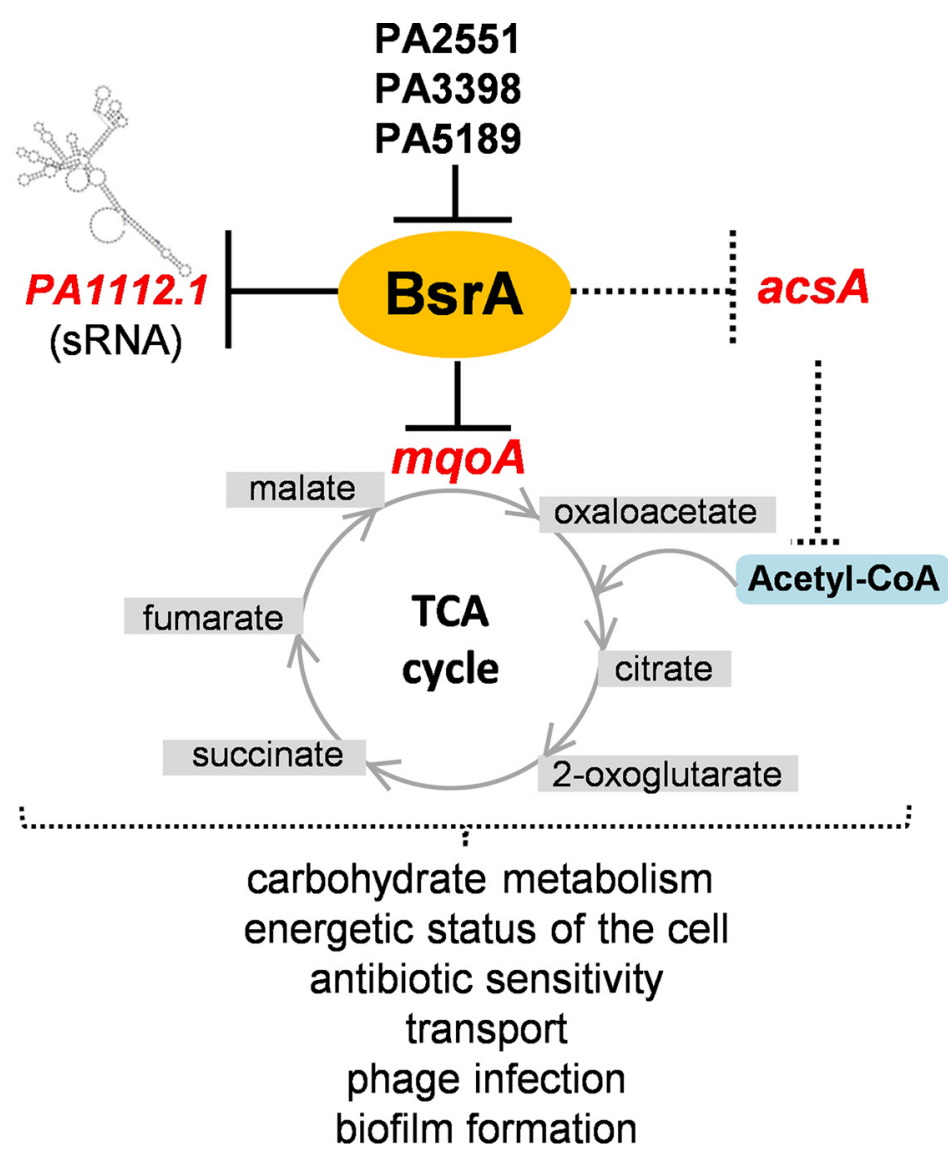

FIG 6 BsrA regulatory network in $P$. aeruginosa and its impact on bacterial physiology. A black solid line indicates direct repression by this transcriptional regulator; a dotted line indicates direct and/or indirect involvement of BsrA in the control of gene expression and downstream processes.

E. coli and Corynebacterium glutamicum as the principal enzymes catalyzing the oxidation of malate $(61,83)$. In Pseudomonas putida the mqo-2 gene, encoding a malate:quinone oxidoreductase 2, is under the control of $\mathrm{Crc}$, the global regulator of carbon catabolite repression (CCR) (84). The assimilation of energetically favorable carbon sources is the main bacterial strategy employed to optimize metabolism and growth. Crc protein together with the RNA chaperone translational repressor $\mathrm{Hfq}$ and small RNA(s) comprise the CCR regulatory system in pseudomonads $(85,86)$. In $P$. aeruginosa, a specific sRNA named $\mathrm{CrcZ}$ has been identified as an antagonist of $\mathrm{Crc}$ and $\mathrm{Hfq}$. $\mathrm{CrCZ}$ binds to the $\mathrm{Crc}$ and $\mathrm{Hfq}$ proteins, trapping and sequestering them. The expression of $\operatorname{crc} Z$ is under the control of a two-component system $\mathrm{CbrA} / \mathrm{CbrB}$, which reacts to carbon source availability $(85,87,88)$. It is clear that a multilevel regulatory network involving sRNAs plays an important role in metabolic regulation in pseudomonads, which is interesting in light of our identification of a sRNA (PA1112.1) as a target of BsrA regulation.

Our analysis of the phenotype of the bsrA-deficient mutant demonstrated its increased fitness in the presence of kanamycin compared to the WT strain under specific conditions. It was previously recognized that the efficacy of aminoglycoside antibiotics depends on metabolic stimuli $(74,89,90)$. As an aminoglycoside, kanamycin acts by inhibiting protein synthesis through binding to the $30 \mathrm{~S}$ subunit of the bacterial ribosome. Killing of bacterial cells by kanamycin depends on proton-motive force (PMF), which is required for the uptake of the antibiotic (89). PMF is related to the NADH level, which is dependent on metabolism. Therefore, the cellular metabolic state modulates the uptake and/or efficacy of the antibiotic (90). Although adaptation to antibiotics is thought to be controlled at the transcriptional level by the induction of 
stress responses, several reports have indicated that there is a relationship between a high concentration of certain endogenous metabolites and the level of bacterial resistance (91-94). We found that the $\Delta b s r A$ mutant displayed better adaptation to kanamycin under conditions of acetate supplementation, and it may be speculated that this is due to altered drug uptake due to changes in PMF generation, a process connected with the TCA cycle and cellular respiration $(89,90,95)$. Growth on acetate requires the activity of the glyoxylate shunt which supplies cells with malate and oxaloacetate (Fig. 4A). It might be connected with reoxidization of the $\mathrm{NADH}$ excess generated by the TCA cycle during growth on acetate and the need to coordinate the composition of the electron transport chain at the level of the terminal oxidases, e.g., the proton pumping NADH dehydrogenase I or Nqr (73). The $\triangle b s r A$ mutant had an increased level of the transcript of malate dehydrogenase $m q o A$ (Fig. $3 \mathrm{~J}$ ) and probably those encoding several other enzymes from the TCA cycle and acetate metabolism. The lack of repression of TCA cycle enzymes or genes involved in acetate metabolism in the $\triangle b s r A$ mutant in comparison to the WT strain may provide some advantage during growth on acetate in the presence of kanamycin and adaptation to the stress caused by this antibiotic.

Kanamycin sensitivity was examined in cells grown on other carbon sources, but a significant difference in antibiotic adaptation of the $\Delta b s r A$ mutant was only observed with acetate supplementation. The main reason for this may be the stage at which particular carbon compounds enter the TCA cycle, as shown by Dolan et al. (73). These authors presented so-called "carbon fluxes" leading to metabolic and transcriptomic changes caused by growth on acetate or glycerol. We speculate that the lack of BsrA leads to elevated TCA cycle flux connected with metabolism remodeling when acetate is the sole carbon source.

An interesting gene belonging to the BsrA regulon, potentially connected with TCA cycle remodeling, is PA5445. This gene putatively encodes succinyl-CoA/acetate CoAtransferase, an enzyme engaged in the conversion of succinyl-CoA and acetate to succinate and acetyl-CoA, which could modulate the TCA cycle and confer some advantage during growth on acetate. PA5445 displays almost 50\% identity to AarC from Acetobacter aceti, a bacterium utilizing a specialized TCA cycle (71). In this bacterium AarC-mediated conversion of succinyl-CoA to succinate replaces the action of typical succinyl-CoA synthetases (SucC and SucD) $(71,96)$. This modification is connected with enhanced tolerance to low $\mathrm{pH}$ and acetate, produced by Acetobacter during fermentation. Many bacteria, including $P$. aeruginosa, possess homologues of aarC (asct) in addition to the sucC and sucD genes, which suggests the existence of an alternative pathway in the TCA cycle, possibly conferring some advantage connected with acetate metabolism (96).

Similar to mqoAp, the promoter region of PA5445 possesses few potential BsrA binding sites (matching the consensus in Fig. 2F), with one putative site (TTCGACCTTGGTA) overlapping the predicted -10 promoter region and located very close to a BsrA ChIP-seq peak summit. This suggests that BsrA may regulate genes encoding components of metabolic pathways and can mediate metabolism remodeling, which could lead to increased fitness of the $\triangle b s r A$ mutant in the presence of kanamycin.

Interestingly, bsrA (PA2121) was identified as one of a panel of genes containing mutations in $P$. aeruginosa cystic fibrosis isolates, which may have been selected during adaptation and evolution to promote survival during infection of the lungs of these patients (97-99). In addition, Kong et al. (100), using a luxCDABE-based random promoter library of $P$. aeruginosa PAO1, identified PA2121 (bsrA) as 1 of 45 genes that perform a role in long-term survival and thus may be involved in chronic infections of the human body.

BsrA binds to numerous sites in the $P$. aeruginosa genome, and yet it only had a limited influence on the regulation of gene expression under the conditions tested (see Data Set S3). The majority of BsrA binding sites contain the LTTR box, composed of the sequence $T-\mathrm{N}_{11}-\mathrm{A}$, but besides this element there is a low level of sequence 
conservation. It was not possible to define a more specific binding motif, which suggests the involvement of other factors in mediating BsrA binding to DNA. This observation highlights the potentially broad role of BsrA in modulating gene expression in $P$. aeruginosa, with the possible involvement of other regulatory proteins that associate with sequences adjacent to BsrA binding sites under specific growth conditions. The nature of the signal to which BsrA responds and the precise role of this factor require further study.

Recently, high-throughput SELEX analysis has been used to define the preferred binding motifs of $53 P$. aeruginosa LysR-type transcriptional regulators (101). Most of these LTTRs display dimeric binding to cognate sequences. The recognized binding sites are mostly palindromic or have partial dyad symmetry and range in length from 12 to $24 \mathrm{bp}$. Sequence conservation is highest within the flanking regions, that usually display dyad symmetry, whereas there is often very low sequence conservation inside the motif. In most of the binding sites the LTTR-box (T-N11-A, T-N10-A, or T-N9-A) can be identified as part of the sequence creating dyad symmetry. The motif preferentially recognized by BsrA was identified as NAGTAGACNNGTCTACTN; however, no such sequence was found in the genomes of PAO1 or PAO1161, and no highly similar sequences were present in the regions identified using ChIP-seq analysis. FIMO analysis (102) using 200-bp sequences encompassing the BsrA peak summits identified only 5 sequences with a $P$ value of $<0.0001$ resembling the proposed motif (peaks 682, 194, 367,276 , and 157 [see Data Set S3]) or 56 sequences when a $P$ value cutoff of 0.001 was used. The preferential BsrA binding site motif identified in our analysis is more generic but is recognizable as an LTTR box characteristic for LysR-type regulators and better explains the presence of multiple LTTR binding sites within the promoters of cognate genes.

LTTRs usually bind to promoters of target genes upstream from the transcription start site. Among the tested promoter regions of BsrA regulated genes, i.e., bsrA, mqoA, and PA1112.1, two to four $\mathrm{T}-\mathrm{N}_{11}$-A motifs, closely resembling the BsrA binding site (Fig. 2F) were identified (Fig. 3A to C). These are located at positions from 3 to $184 \mathrm{bp}$ from the start codon of these downregulated genes, so that BsrA binding to these sites might reduce RNA polymerase access to the core promoter sequences $(-10,-35)$. To specifically recognize and bind cognate DNA, LTTRs use highly conserved interactions between amino acids and nucleotide bases as well as numerous less conserved secondary interactions $(7,68)$. One site, often called the recognition binding site, consists of a $\mathrm{T}-\mathrm{N}_{11}$-A motif with imperfect dyad symmetry. It is believed that interaction with this site anchors the LTTR to the DNA and is often involved in repression, including autoregulation. LTTRs are known to bind to longer sequences (50 to $60 \mathrm{bp}$ ) containing a so-called activation binding site, and these interactions are usually driven by the presence of a specific ligand or cofactor, which is bound by the LTTR. In addition, LTTRs bind with higher or lower affinity to their binding sites depending on the presence or absence of its inducer or ligand, which modulates interaction with DNA. Conformational flexibility of the created LTTR multimers (usually tetramers) causes DNA bending or relaxation, which regulates the repression or activation state of the regulator (13). Conformational changes may also permit transient contacts of the regulator with DNA sequences flanking the $\mathrm{T}-\mathrm{N}_{11}-\mathrm{A}$ motif, which might also be affected by occupation by other DNA-interacting factors. The availability of the regulator in the cell, the possibility of creating monomers or multimers to exert a regulatory effect on target promoters, and the dynamic order in which different binding events take place could provide further levels of control. Our pull-down results highlighted the existence of an intricate regulatory network engaging in possible cross talk, cooperation, and/or interconnection between different transcriptional regulators exerting an influence on bsrA expression and further on its targets. Thus, different factors control LTTR interactions with DNA, providing specificity of recognition and correct timing of this action.

Based on the presented results, we propose a model of the regulatory network engaging BsrA in P. aeruginosa and its impact on bacterial physiology (Fig. 6). BsrA acts 
as the repressor of genes involved in carbohydrate metabolism ( $m q \circ A$ and acs $A$ ) influencing the TCA cycle, the availability of acetyl-CoA, and overall cellular metabolism. In addition, BsrA regulates the transcription of the uncharacterized SRNA PA1112.1, which is possibly involved in posttranscriptional regulation of gene expression. Interestingly, besides autoregulation, the bsrA gene is under the control of other LTTRs of $P$. aeruginosa (PA2551, PA3398, and PA5189), indicating the ability to fine-tune the BsrA action in the cell. This multilevel regulatory network plays a role in controlling carbohydrate metabolism (TCA cycle, acetate, and pyruvate metabolism) and thus the energetic status of the cell, which has implications for other functions such as cellular transport, the response to antibiotic, phage infection, biofilm formation, virulence, and overall survival strategies. In line with this model, the induction of bsrA expression was observed in the presence of antibiotics and also in parA and parB mutants characterized by growth retardation and defects in chromosome distribution (103), which suggests the release of bsrA expression in response to stress and the need to redirect metabolism to cope with adverse conditions, that might be manifested by a slowdown of bacterial growth.

\section{MATERIALS AND METHODS}

Bacterial strains, plasmids, and growth experiments. Bacterial strains used and constructed in this study (listed in Table S1) were grown in LB or on LB-agar medium at $37^{\circ} \mathrm{C}$ and in M9 minimal medium supplemented with sodium citrate $(0.25 \%)$ or sodium acetate $(20 \mathrm{mM})$ as the carbon source, with leucine $(10 \mathrm{mM})$ added in the case of $P$. aeruginosa PAO1161 leu mutant strains. For the selection of plasmids in $E$. coli, media were supplemented with $10 \mu \mathrm{g} / \mathrm{ml}$ chloramphenicol, $50 \mu \mathrm{g} / \mathrm{ml}$ kanamycin or benzylpenicillin at a final concentration of $150 \mu \mathrm{g} / \mathrm{ml}$ in liquid medium or $300 \mu \mathrm{g} / \mathrm{ml}$ in agar plates. For $P$. aeruginosa strains, carbenicillin $(300 \mu \mathrm{g} / \mathrm{ml})$, rifampin $(300 \mu \mathrm{g} / \mathrm{ml})$, kanamycin $(250 \mu \mathrm{g} / \mathrm{ml}$ in liquid medium; $500 \mu \mathrm{g} / \mathrm{ml}$ in plates), and chloramphenicol (75 $\mu \mathrm{g} / \mathrm{ml}$ in liquid medium; $150 \mu \mathrm{g} / \mathrm{ml}$ in plates) were applied as required.

For growth experiments, liquid media were inoculated with strains propagated on plates. These cultures were grown overnight with shaking at $37^{\circ} \mathrm{C}$, diluted 1:100 in fresh medium, and then incubation was continued. Bacterial growth was monitored by the measurement of optical density at $600 \mathrm{~nm}$ $\left(\mathrm{OD}_{600}\right)$ at $1 \mathrm{~h}$ interval. Competent $E$. coli cells were prepared by treatment with $\mathrm{CaCl}_{2}$, and transformation was performed according to a standard procedure (104). Competent $P$. aeruginosa cells were prepared as described previously (105).

All plasmids used and constructed in this study are described in Table S1.

A P. aeruginosa PAO1161 $\Delta b s r A$ mutant was obtained by allele exchange (106). Competent cells of $E$. coli S17-1 were transformed with plasmid pMEB14 (a derivative of suicide vector pAKE600) to create the donor strain, and WT $P$. aeruginosa PAO1161 Rif' was used as the recipient. The allele exchange procedure was performed as described previously $(106,107)$. Verification of the obtained mutant strain was performed by PCR using primer pair 4/7 (see Table S2).

Measurements of biofilm amounts. Biofilm analyses were performed with the crystal violet staining method according to a previously described method (104). Bacteria were incubated in LB or M9 minimal medium with supplements as indicated.

Motility assays. Motility assays were performed as described previously (79), supplementing the swimming, swarming, and twitching media, if necessary, with chloramphenicol $(150 \mu \mathrm{g} / \mathrm{ml})$ and IPTG (0.05 mM). To standardize the assays, all plates contained the same volume of the medium.

RNA isolation, RNA-seq, and RT-qPCR. Total RNA was isolated from three independent replicate samples of $P$. aeruginosa PAO1161 overexpressing the bsrA gene, as well as the control strain carrying the empty vector or $P$. aeruginosa PAO1161 WT and the $\Delta b s r A$ strain. RNA isolation and analysis were performed as described in Text S1 in the supplemental material.

Chromatin immunoprecipitation with sequencing. ChIP was performed according to the procedure of Kawalek et al. (108) with some modifications, as described in Text S1.

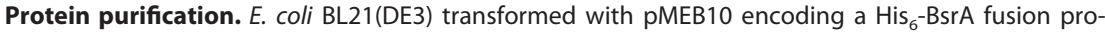
tein was grown to exponential phase in autoinduction LB medium (Foremedium) containing 1\% (vol/ vol) glycerol and $0.5 \%(\mathrm{wt} / \mathrm{vol}) \mathrm{NaCl}$. The cells were harvested by centrifugation, resuspended in phosphate buffer ( $50 \mathrm{mM}$ sodium phosphate $[\mathrm{pH} 8.0]$ ) supplemented with lysozyme ( $1 \mathrm{mg} / \mathrm{ml})$, phenylmethylsulfonyl fluoride ( $1 \mathrm{mM}$ ), and benzonase nuclease (250 U; Sigma), and then sonicated. His ${ }_{6}$-BsrA was purified from the cell lysate by chromatography on Ni-agarose columns (Protino Ni-TED 1000; MachereyNagel) with $300 \mathrm{mM}$ imidazole in phosphate buffer used for elution. The purification procedure was monitored by SDS-PAGE using a Pharmacia PHAST gel system. Fractions containing the purified protein were dialyzed overnight in Tris buffer containing $5 \%$ ( $\mathrm{vol} / \mathrm{vol}) \mathrm{glycerol}$ and stored in small aliquots at $-80^{\circ} \mathrm{C}$.

In vitro protein-DNA interactions. An EMSA was performed to determine the ability of purified BsrA to bind to selected promoter regions of $P$. aeruginosa genes in vitro, as described in Text $\mathrm{S} 1$.

Regulatory experiments with promoter-xyIE fusions in $\boldsymbol{E}$. coli. E. coli DH5 $\alpha$ double transformants carrying PPT01 derivatives with the promoter regions of selected $P$. aeruginosa genes fused to the $x y I E$ 
reporter gene plus pAMB9.37 (lac/9-tacp) derivatives expressing the tested proteins were assayed for catechol 2,3-oxygenase activity (the product of $x y(E)$, as described in Text S1.

Tests of kanamycin sensitivity. The effect of kanamycin on PAO1161 cells was tested using the carbon source screening procedure $(74,89)$ described in Text S1.

DNA pull-down assay. Pull-down analysis was performed as described previously (108), with modifications summarized in Text S1.

Data availability. The raw RNA-seq and ChIP-seq data supporting the results of this article were deposited in the NCBI's Gene Expression Omnibus (GEO) database (http://www.ncbi.nlm.nih.gov/geo/) under GEO Series accession numbers GSE163234 and GSE163233.

\section{SUPPLEMENTAL MATERIAL}

Supplemental material is available online only.

FIG S1, TIF file, 1.5 MB.

FIG S2, TIF file, 1.1 MB.

DATA SET S1, XLSX file, 4.7 MB.

DATA SET S2, XLSX file, 0.05 MB.

DATA SET S3, XLSX file, $0.2 \mathrm{MB}$.

DATA SET S4, XLSX file, 0.01 MB.

TEXT S1, DOCX file, $0.03 \mathrm{MB}$.

TABLE S1, DOCX file, $0.02 \mathrm{MB}$.

TABLE S2, DOCX file, $0.02 \mathrm{MB}$.

\section{ACKNOWLEDGMENTS}

We thank Jan Gawor, Karolina Zuchniewicz, and Robert Gromadka from the Laboratory of DNA Sequencing and Oligonucleotide Synthesis, IBB PAS, Warsaw, Poland, for performing RNA and DNA sequencing. We thank the Laboratory of Mass Spectrometry of IBB PAS, Warsaw, Poland, for the analysis of pull-down samples.

This study was supported by the National Science Centre in Poland (grant 2015/18/ E/NZ2/00675).

\section{REFERENCES}

1. Maddocks SE, Oyston PCF. 2008. Structure and function of the LysR-type transcriptional regulator (LTTR) family proteins. Microbiology (Reading) 154:3609-3623. https://doi.org/10.1099/mic.0.2008/022772-0.

2. Reen FJ, Barret M, Fargier E, O'Muinneacháin M, O'Gara F. 2013. Molecular evolution of LysR-type transcriptional regulation in Pseudomonas aeruginosa. Mol Phylogenet Evol 66:1041-1049. https://doi.org/10.1016/j ympev.2012.12.014.

3. Henikoff S, Haughn GW, Calvo JM, Wallace JC. 1988. A large family of bacterial activator proteins. Proc Natl Acad Sci U S A 85:6602-6606. https://doi.org/10.1073/pnas.85.18.6602.

4. Schell MA. 1993. Molecular biology of the LysR family of transcriptional regulators. Annu Rev Microbiol 47:597-626. https://doi.org/10.1146/ annurev.mi.47.100193.003121.

5. Housseini B Issa K, Phan G, Broutin I. 2018. Functional mechanism of the efflux pumps transcription regulators from Pseudomonas aeruginosa based on 3D structures. Front Mol Biosci 5:57. https://doi.org/10.3389/ fmolb.2018.00057.

6. Santiago AS, Santos CA, Mendes JS, Toledo MAS, Beloti LL, Souza AA, Souza AP. 2015. Characterization of the LysR-type transcriptional regulator YcjZ-like from Xylella fastidiosa overexpressed in Escherichia coli. Protein Expr Purif 113:72-78. https://doi.org/10.1016/j.pep.2015.05.003.

7. Lochowska A, Iwanicka-Nowicka R, Plochocka D, Hryniewicz MM. 2001. Functional dissection of the LysR-type CysB transcriptional regulator. Regions important for DNA binding, inducer response, oligomerization, and positive control. J Biol Chem 276:2098-2107. https://doi.org/10 .1074/jbc.M007192200.

8. Colyer TE, Kredich NM. 1994. Residue threonine-149 of the Salmonella Typhimurium CysB transcription activator: mutations causing constitutive expression of positively regulated genes of the cysteine regulon. Mol Microbiol 13:797-805. https://doi.org/10.1111/j.1365-2958.1994 .tb00472.x.

9. Colyer TE, Kredich NM. 1996. In vitro characterization of constitutive CysB proteins from Salmonella Typhimurium. Mol Microbiol 21:247-256. https://doi.org/10.1046/j.1365-2958.1996.6301347.x.
10. van Keulen G, Ridder ANJA, Dijkhuizen L, Meijer WG. 2003. Analysis of DNA binding and transcriptional activation by the LysR-type transcriptional regulator CbbR of Xanthobacter flavus. J Bacteriol 185:1245-1252. https://doi.org/10.1128/JB.185.4.1245-1252.2003.

11. Picossi S, Belitsky BR, Sonenshein AL. 2007. Molecular mechanism of the regulation of Bacillus subtilis gltAB expression by GltC. J Mol Biol 365:1298-1313. https://doi.org/10.1016/j.jmb.2006.10.100.

12. Momany C, Neidle EL. 2012. Defying stereotypes: the elusive search for a universal model of LysR-type regulation. Mol Microbiol 83:453-456. https://doi.org/10.1111/j.1365-2958.2011.07960.x.

13. Monferrer D, Tralau T, Kertesz MA, Dix I, Solà M, Usón I. 2010. Structural studies on the full-length LysR-type regulator TsaR from Comamonas testosteroni T-2 reveal a novel open conformation of the tetrameric LTTR fold. Mol Microbiol 75:1199-1214. https://doi.org/10.1111/j.1365-2958 2010.07043.x

14. Porrúa O, García-Jaramillo M, Santero E, Govantes F. 2007. The LysR-type regulator AtzR binding site: DNA sequences involved in activation, repression and cyanuric acid-dependent repositioning. Mol Microbiol 66:410-427. https://doi.org/10.1111/j.1365-2958.2007.05927.x.

15. Nguyen Le Minh P, Velázquez Ruiz C, Vandermeeren S, Abwoyo $P$, Bervoets I, Charlier D. 2018. Differential protein-DNA contacts for activation and repression by ArgP, a LysR-type (LTTR) transcriptional regulator in Escherichia coli. Microbiol Res 206:141-158. https://doi.org/10.1016/j micres.2017.10.009.

16. Lerche M, Dian C, Round A, Lönneborg R, Brzezinski P, Leonard GA. 2016. The solution configurations of inactive and activated DntR have implications for the sliding dimer mechanism of LysR transcription factors. Sci Rep 6:19988. https://doi.org/10.1038/srep19988.

17. Muraoka S, Okumura R, Ogawa N, Nonaka T, Miyashita K, Senda T. 2003. Crystal structure of a full-length LysR-type transcriptional regulator, CbnR: unusual combination of two subunit forms and molecular bases for causing and changing DNA bend. J Mol Biol 328:555-566. https://doi .org/10.1016/S0022-2836(03)00312-7. 
18. Parkins MD, Somayaji R, Waters VJ. 2018. Epidemiology, biology, and impact of clonal Pseudomonas aeruginosa infections in cystic fibrosis. Clin Microbiol Rev 31:e00019-18. https://doi.org/10.1128/CMR.00019-18.

19. Pachori P, Gothalwal R, Gandhi P. 2019. Emergence of antibiotic resistance Pseudomonas aeruginosa in intensive care unit; a critical review. Genes Dis 6:109-119. https://doi.org/10.1016/j.gendis.2019.04.001.

20. Shigemura K, Arakawa S, Sakai Y, Kinoshita S, Tanaka K, Fujisawa M. 2006. Complicated urinary tract infection caused by Pseudomonas aeruginosa in a single institution (1999-2003). Int J Urol 13:538-542. https:// doi.org/10.1111/j.1442-2042.2006.01359.x.

21. de Oliveira FP, Pires BMFB, de Cássia Ferreira de Almeida Silva K, de Carvalho BTF, Teixeira LA, de Paula GR, de Oliveira BGRB. 2017. Prevalence, antimicrobial susceptibility, and clonal diversity of Pseudomonas aeruginosa in chronic wounds. J Wound Ostomy Continence Nurs 44:528-535. https://doi.org/10.1097/WON.0000000000000373.

22. Silvestre JF, Betlloch MI. 1999. Cutaneous manifestations due to Pseudomonas infection. Int J Dermatol 38:419-431. https://doi.org/10.1046/j .1365-4362.1999.00606.x.

23. Stover CK, Pham XQ, Erwin AL, Mizoguchi SD, Warrener P, Hickey MJ, Brinkman FS, Hufnagle WO, Kowalik DJ, Lagrou M, Garber RL, Goltry L, Tolentino E, Westbrock-Wadman S, Yuan Y, Brody LL, Coulter SN, Folger KR, Kas A, Larbig K, Lim R, Smith K, Spencer D, Wong GK, Wu Z, Paulsen IT, Reizer J, Saier MH, Hancock RE, Lory S, Olson MV. 2000. Complete genome sequence of Pseudomonas aeruginosa PAO1, an opportunistic pathogen. Nature 406:959-964. https://doi.org/10.1038/35023079.

24. Yao X, He W, Lu C-D. 2011. Functional characterization of seven $\gamma$-glutamylpolyamine synthetase genes and the bauRABCD locus for polyamine and $\beta$-alanine utilization in Pseudomonas aeruginosa PAO1. J Bacteriol 193:3923-3930. https://doi.org/10.1128/JB.05105-11.

25. Panasia G, Oetermann S, Steinbüchel A, Philipp B. 2019. Sulfate ester detergent degradation in Pseudomonas aeruginosa is subject to both positive and negative regulation. Appl Environ Microbiol 85:e01352-19. https://doi.org/10.1128/AEM.01352-19.

26. Heacock-Kang Y, Zarzycki-Siek J, Sun Z, Poonsuk K, Bluhm AP, Cabanas D, Fogen D, McMillan IA, Chuanchuen R, Hoang TT. 2018. Novel dual regulators of Pseudomonas aeruginosa essential for productive biofilms and virulence. Mol Microbiol 109:401-414. https://doi.org/10.1111/mmi.14063.

27. Nakada Y, Itoh Y. 2002. Characterization and regulation of the gbuA gene, encoding guanidinobutyrase in the arginine dehydrogenase pathway of Pseudomonas aeruginosa PAO1. J Bacteriol 184:3377-3384. https://doi.org/10.1128/JB.184.12.3377-3384.2002.

28. Wargo MJ, Hogan DA. 2009. Identification of genes required for Pseudomonas aeruginosa carnitine catabolism. Microbiology (Reading) 155:2411-2419. https://doi.org/10.1099/mic.0.028787-0.

29. Martínez E, Cosnahan RK, Wu M, Gadila SK, Quick EB, Mobley JA, Campos-Gómez J. 2019. Oxylipins mediate cell-to-cell communication in Pseudomonas aeruginosa. Commun Biol 2:66. https://doi.org/10.1038/ s42003-019-0310-0.

30. Reen FJ, Haynes JM, Mooij MJ, O'Gara F. 2013. A non-classical LysR-type transcriptional regulator PA2206 is required for an effective oxidative stress response in Pseudomonas aeruginosa. PLoS One 8:e54479. https:// doi.org/10.1371/journal.pone.0054479.

31. Carty NL, Layland N, Colmer-Hamood JA, Calfee MW, Pesci EC, Hamood AN. 2006. PtxR modulates the expression of QS-controlled virulence factors in the Pseudomonas aeruginosa strain PAO1. Mol Microbiol 61:782-794. https://doi.org/10.1111/j.1365-2958.2006.05269.x.

32. Turner KH, Vallet-Gely I, Dove SL. 2009. Epigenetic control of virulence gene expression in Pseudomonas aeruginosa by a LysR-type transcription regulator. PLoS Genet 5:e1000779. https://doi.org/10.1371/journal.pgen .1000779 .

33. Rakhimova E, Munder A, Wiehlmann L, Bredenbruch F, Tümmler B. 2008. Fitness of isogenic colony morphology variants of Pseudomonas aeruginosa in murine airway infection. PLoS One 3:e1685. https://doi.org/10 .1371/journal.pone.0001685.

34. Hall CW, Zhang L, Mah T-F. 2017. PA3225 Is a Transcriptional repressor of antibiotic resistance mechanisms in Pseudomonas aeruginosa. Antimicrob Agents Chemother 61:e02114-16. https://doi.org/10.1128/AAC .02114-16.

35. Yeung ATY, Torfs ECW, Jamshidi F, Bains M, Wiegand I, Hancock REW, Overhage J. 2009. Swarming of Pseudomonas aeruginosa is controlled by a broad spectrum of transcriptional regulators, including MetR. J Bacteriol 191:5592-5602. https://doi.org/10.1128/JB.00157-09.
36. Willsey GG, Wargo MJ. 2016. Sarcosine catabolism in Pseudomonas aeruginosa is transcriptionally regulated by SouR. J Bacteriol 198:301-310. https://doi.org/10.1128/JB.00739-15.

37. Balasubramanian D, Kumari H, Mathee K. 2015. Pseudomonas aeruginosa AmpR: an acute-chronic switch regulator. Pathog Dis 73:1-14. https:// doi.org/10.1111/2049-632X.12208.

38. Vercammen K, Wei Q, Charlier D, Dötsch A, Haüssler S, Schulz S, Salvi F, Gadda G, Spain J, Rybtke ML, Tolker-Nielsen T, Dingemans J, Ye L, Cornelis P. 2015. Pseudomonas aeruginosa LysR PA4203 regulator NmoR acts as a repressor of the PA4202 $\mathrm{nmoA}$ gene, encoding a nitronate monooxygenase. J Bacteriol 197:1026-1039. https://doi.org/10.1128/JB 01991-14.

39. Kukavica-Ibrulj I, Sanschagrin F, Peterson A, Whiteley M, Boyle B, MacKay J, Levesque RC. 2008. Functional genomics of PycR, a LysR family transcriptional regulator essential for maintenance of Pseudomonas aeruginosa in the rat lung. Microbiology (Reading) 154:2106-2118. https://doi .org/10.1099/mic.0.2007/011239-0.

40. Cao H, Krishnan G, Goumnerov B, Tsongalis J, Tompkins R, Rahme LG. 2001. A quorum sensing-associated virulence gene of Pseudomonas aeruginosa encodes a LysR-like transcription regulator with a unique selfregulatory mechanism. Proc Natl Acad Sci U S A 98:14613-14618. https://doi.org/10.1073/pnas.251465298.

41. Maura D, Hazan R, Kitao T, Ballok AE, Rahme LG. 2016. Evidence for direct control of virulence and defense gene circuits by the Pseudomonas aeruginosa quorum sensing regulator, MvfR. Sci Rep 6:34083. https://doi.org/ 10.1038/srep34083.

42. Huang H, Shao X, Xie Y, Wang T, Zhang Y, Wang X, Deng X. 2019. An integrated genomic regulatory network of virulence-related transcriptional factors in Pseudomonas aeruginosa. Nat Commun 10:2931. https://doi .org/10.1038/s41467-019-10778-w.

43. Ochsner UA, Vasil ML, Alsabbagh E, Parvatiyar K, Hassett DJ. 2000. Role of the Pseudomonas aeruginosa oxyR-recG operon in oxidative stress defense and DNA repair: OxyR-dependent regulation of $k a t B$-ankB, ahpB, and $a h p C-a h p F$. J Bacteriol 182:4533-4544. https://doi.org/10.1128/JB 182.16.4533-4544.2000.

44. Wei Q, Minh PNL, Dötsch A, Hildebrand F, Panmanee W, Elfarash A, Schulz S, Plaisance S, Charlier D, Hassett D, Häussler S, Cornelis P. 2012. Global regulation of gene expression by OxyR in an important human opportunistic pathogen. Nucleic Acids Res 40:4320-4333. https://doi .org/10.1093/nar/gks017.

45. Vinckx T, Wei Q, Matthijs S, Cornelis P. 2010. The Pseudomonas aeruginosa oxidative stress regulator OxyR influences production of pyocyanin and rhamnolipids: protective role of pyocyanin. Microbiology (Reading) 156:678-686. https://doi.org/10.1099/mic.0.031971-0.

46. Köhler T, Michéa-Hamzehpour M, Henze U, Gotoh N, Curty LK, Pechère JC. 1997. Characterization of MexE-MexF-OprN, a positively regulated multidrug efflux system of Pseudomonas aeruginosa. Mol Microbiol 23:345-354. https://doi.org/10.1046/j.1365-2958.1997.2281594.x.

47. Sobel ML, Neshat S, Poole K. 2005. Mutations in PA2491 (mexS) promote MexT-dependent mexEF-oprN expression and multidrug resistance in a clinical strain of Pseudomonas aeruginosa. J Bacteriol 187:1246-1253. https://doi.org/10.1128/JB.187.4.1246-1253.2005.

48. McGrath S, Wade DS, Pesci EC. 2004. Dueling quorum sensing systems in Pseudomonas aeruginosa control the production of the Pseudomonas quinolone signal (PQS). FEMS Microbiol Lett 230:27-34. https://doi.org/ 10.1016/S0378-1097(03)00849-8.

49. García-Reyes S, Soberón-Chávez G, Cocotl-Yanez M. 2020. The third quorum-sensing system of Pseudomonas aeruginosa: Pseudomonas quinolone signal and the enigmatic PqsE protein. J Med Microbiol 69:25-34. https://doi.org/10.1099/jmm.0.001116.

50. Déziel E, Gopalan S, Tampakaki AP, Lépine F, Padfield KE, Saucier M, Xiao G, Rahme LG. 2005. The contribution of MvfR to Pseudomonas aeruginosa pathogenesis and quorum sensing circuitry regulation: multiple quorum sensing-regulated genes are modulated without affecting lasRl, $r h / R I$ or the production of $\mathrm{N}$-acyl-L-homoserine lactones. Mol Microbiol 55:998-1014. https://doi.org/10.1111/j.1365-2958.2004.04448.x.

51. Xiao G, He J, Rahme LG. 2006. Mutation analysis of the Pseudomonas aeruginosa mvfR and pqsABCDE gene promoters demonstrates complex quorum-sensing circuitry. Microbiology (Reading) 152:1679-1686. https://doi .org/10.1099/mic.0.28605-0.

52. Heo Y-J, Chung I-Y, Cho W-J, Lee B-Y, Kim J-H, Choi K-H, Lee J-W, Hassett DJ, Cho Y-H. 2010. The major catalase gene (katA) of Pseudomonas aeruginosa PA14 is under both positive and negative control of the global 
transactivator OxyR in response to hydrogen peroxide. J Bacteriol 192:381-390. https://doi.org/10.1128/JB.00980-09.

53. Vinckx T, Matthijs S, Cornelis P. 2008. Loss of the oxidative stress regulator OxyR in Pseudomonas aeruginosa PAO1 impairs growth under ironlimited conditions. FEMS Microbiol Lett 288:258-265. https://doi.org/10 .1111/j.1574-6968.2008.01360.x.

54. Köhler T, Epp SF, Curty LK, Pechère JC. 1999. Characterization of MexT, the regulator of the MexE-MexF-OprN multidrug efflux system of Pseudomonas aeruginosa. J Bacteriol 181:6300-6305. https://doi.org/10 .1128/JB.181.20.6300-6305.1999.

55. Yang X, Zhang Z, Huang Z, Zhang X, Li D, Sun L, You J, Pan X, Yang H. 2019. A putative LysR-type transcriptional regulator inhibits biofilm synthesis in Pseudomonas aeruginosa. Biofouling 35:541-550. https://doi .org/10.1080/08927014.2019.1627337.

56. You J, Sun L, Yang X, Pan X, Huang Z, Zhang X, Gong M, Fan Z, Li L, Cui X, Jing Z, Jin S, Rao Z, Wu W, Yang H. 2018. Regulatory protein SrpA controls phage infection and core cellular processes in Pseudomonas aeruginosa. Nat Commun 9:1846. https://doi.org/10.1038/s41467-018-04232-6.

57. Kawalek A, Kotecka K, Modrzejewska M, Gawor J, Jagura-Burdzy G, Bartosik AA. 2020. Genome sequence of Pseudomonas aeruginosa PAO1161, a PAO1 derivative with the ICEPae1161 integrative and conjugative element. BMC Genomics 21:14. https://doi.org/10.1186/s12864 -019-6378-6.

58. Römling U. 2015. Small molecules with big effects: Cyclic di-GMP-mediated stimulation of cellulose production by the amino acid L-arginine. Sci Signal 8:fs12. https://doi.org/10.1126/scisignal.aac4734.

59. Kumar A, Ting Y-P. 2016. Streptomycin favors biofilm formation by altering cell surface properties. Appl Microbiol Biotechnol 100:8843-8853. https://doi.org/10.1007/s00253-016-7793-0.

60. Winsor GL, Griffiths EJ, Lo R, Dhillon BK, Shay JA, Brinkman FSL. 2016. Enhanced annotations and features for comparing thousands of Pseudomonas genomes in the Pseudomonas genome database. Nucleic Acids Res 44:D646-D653. https://doi.org/10.1093/nar/gkv1227.

61. Molenaar D, van der Rest ME, Petrović S. 1998. Biochemical and genetic characterization of the membrane-associated malate dehydrogenase (acceptor) from Corynebacterium glutamicum. Eur J Biochem 254:395-403. https://doi.org/10.1046/j.1432-1327.1998.2540395.x.

62. Kumari S, Tishel R, Eisenbach M, Wolfe AJ. 1995. Cloning, characterization, and functional expression of acs, the gene which encodes acetyl coenzyme A synthetase in Escherichia coli. J Bacteriol 177:2878-2886. https://doi.org/10.1128/jb.177.10.2878-2886.1995.

63. Morita Y, Tomida J, Kawamura Y. 2012. MexXY multidrug efflux system of Pseudomonas aeruginosa. Front Microbiol 3:408. https://doi.org/10 .3389/fmicb.2012.00408.

64. Singh M, Yau YCW, Wang S, Waters V, Kumar A. 2017. MexXY efflux pump overexpression and aminoglycoside resistance in cystic fibrosis isolates of Pseudomonas aeruginosa from chronic infections. Can J Microbiol 63:929-938. https://doi.org/10.1139/cjm-2017-0380.

65. Kawalek A, Modrzejewska M, Zieniuk B, Bartosik AA, Jagura-Burdzy G. 2019. Interaction of ArmZ with the DNA-binding domain of MexZ induces expression of mexXY multidrug efflux pump genes and antimicrobial resistance in Pseudomonas aeruginosa. Antimicrob Agents Chemother 63:e01199-19. https://doi.org/10.1128/AAC.01199-19.

66. Bailey TL, Boden M, Buske FA, Frith M, Grant CE, Clementi L, Ren J, Li WW, Noble WS. 2009. MEME SUITE: tools for motif discovery and searching. Nucleic Acids Res 37:W202-W208. https://doi.org/10.1093/nar/gkp335.

67. Kullik I, Stevens J, Toledano MB, Storz G. 1995. Mutational analysis of the redox-sensitive transcriptional regulator OxyR: regions important for DNA binding and multimerization. J Bacteriol 177:1285-1291. https://doi .org/10.1128/jb.177.5.1285-1291.1995.

68. Alanazi AM, Neidle EL, Momany C. 2013. The DNA-binding domain of BenM reveals the structural basis for the recognition of a T-N11-A sequence motif by LysR-type transcriptional regulators. Acta Crystallogr D Biol Crystallogr 69:1995-2007. https://doi.org/10.1107/ S0907444913017320.

69. González N, Heeb S, Valverde C, Kay E, Reimmann C, Junier T, Haas D. 2008. Genome-wide search reveals a novel GacA-regulated small RNA in Pseudomonas species. BMC Genomics 9:167. https://doi.org/10.1186/ 1471-2164-9-167.

70. Jacob K, Rasmussen A, Tyler P, Servos MM, Sylla M, Prado C, Daniele E, Sharp JS, Purdy AE. 2017. Regulation of acetyl-CoA synthetase transcription by the CrbS/R two-component system is conserved in genetically diverse environmental pathogens. PLoS One 12:e0177825. https://doi .org/10.1371/journal.pone.0177825.
71. Mullins EA, Francois JA, Kappock TJ. 2008. A specialized citric acid cycle requiring succinyl-coenzyme $A$ (CoA):acetate CoA-transferase (AarC) confers acetic acid resistance on the acidophile Acetobacter aceti. J Bacteriol 190:4933-4940. https://doi.org/10.1128/JB.00405-08.

72. Durica-Mitic S, Göpel Y, Görke B. 2018. Carbohydrate utilization in bacteria: making the most out of sugars with the help of small regulatory RNAs. Microbiol Spectr 6:RWR-0013-2017. https://doi.org/10.1128/microbiolspec .RWR-0013-2017.

73. Dolan SK, Kohlstedt M, Trigg S, Vallejo Ramirez P, Kaminski CF, Wittmann C, Welch M. 2020. Contextual flexibility in Pseudomonas aeruginosa central carbon metabolism during growth in single carbon sources. mBio 11:e02684-19. https://doi.org/10.1128/mBio.02684-19.

74. Meylan S, Porter CBM, Yang JH, Belenky P, Gutierrez A, Lobritz MA, Park J, Kim SH, Moskowitz SM, Collins JJ. 2017. Carbon sources tune antibiotic susceptibility in Pseudomonas aeruginosa via tricarboxylic acid cycle control. Cell Chem Biol 24:195-206. https://doi.org/10.1016/j.chembiol.2016 .12.015.

75. Locht C, Geoffroy MC, Renauld G. 1992. Common accessory genes for the Bordetella pertussis filamentous hemagglutinin and fimbriae share sequence similarities with the $p a p C$ and $p a p D$ gene families. EMBO J 11:3175-3183. https://doi.org/10.1002/j.1460-2075.1992.tb05394.x.

76. Giraud C, Bernard CS, Calderon V, Yang L, Filloux A, Molin S, Fichant G, Bordi C, de Bentzmann S. 2011. The PprA-PprB two-component system activates CupE, the first non-archetypal Pseudomonas aeruginosa chaperone-usher pathway system assembling fimbriae. Environ Microbiol 13:666-683. https://doi.org/10.1111/j.1462-2920.2010.02372.x.

77. Burrows LL. 2012. Pseudomonas aeruginosa twitching motility: type IV pili in action. Annu Rev Microbiol 66:493-520. https://doi.org/10.1146/ annurev-micro-092611-150055.

78. Köhler T, Curty LK, Barja F, van Delden C, Pechère JC. 2000. Swarming of Pseudomonas aeruginosa is dependent on cell-to-cell signaling and requires flagella and pili. J Bacteriol 182:5990-5996. https://doi.org/10 .1128/JB.182.21.5990-5996.2000.

79. Rashid MH, Kornberg A. 2000. Inorganic polyphosphate is needed for swimming, swarming, and twitching motilities of Pseudomonas aeruginosa. Proc Natl Acad Sci U S A 97:4885-4890. https://doi.org/10.1073/ pnas.060030097.

80. Jin S, Ishimoto K, Lory S. 1994. Nucleotide sequence of the $r p o N$ gene and characterization of two downstream open reading frames in Pseudomonas aeruginosa. J Bacteriol 176:1316-1322. https://doi.org/10.1128/jb .176.5.1316-1322.1994.

81. Pisithkul T, Schroeder JW, Trujillo EA, Yeesin P, Stevenson DM, Chaiamarit T, Coon JJ, Wang JD, Amador-Noguez D. 2019. Metabolic remodeling during biofilm development of Bacillus subtilis. mBio 10: e00623-19. https://doi.org/10.1128/mBio.00623-19.

82. Kretzschmar U, Rückert A, Jeoung J-H, Görisch H. 2002. Malate:quinone oxidoreductase is essential for growth on ethanol or acetate in Pseudomonas aeruginosa. Microbiology (Reading) 148:3839-3847. https://doi .org/10.1099/00221287-148-12-3839.

83. van der Rest ME, Frank C, Molenaar D. 2000. Functions of the membrane-associated and cytoplasmic malate dehydrogenases in the citric acid cycle of Escherichia coli. J Bacteriol 182:6892-6899. https://doi.org/ 10.1128/JB.182.24.6892-6899.2000.

84. Moreno R, Martínez-Gomariz M, Yuste L, Gil C, Rojo F. 2009. The Pseudomonas putida $\mathrm{Crc}$ global regulator controls the hierarchical assimilation of amino acids in a complete medium: evidence from proteomic and genomic analyses. Proteomics 9:2910-2928. https://doi.org/10.1002/ pmic.200800918.

85. Sonnleitner E, Bläsi U. 2014. Regulation of Hfq by the RNA CrcZ in Pseudomonas aeruginosa carbon catabolite repression. PLoS Genet 10: e1004440. https://doi.org/10.1371/journal.pgen.1004440.

86. Moreno R, Hernández-Arranz S, La Rosa R, Yuste L, Madhushani A, Shingler V, Rojo F. 2015. The Crc and Hfq proteins of Pseudomonas putida cooperate in catabolite repression and formation of ribonucleic acid complexes with specific target motifs. Environ Microbiol 17:105-118. https://doi.org/10.1111/1462-2920.12499.

87. Nishijyo T, Haas D, Itoh Y. 2001. The CbrA-CbrB two-component regulatory system controls the utilization of multiple carbon and nitrogen sources in Pseudomonas aeruginosa. Mol Microbiol 40:917-931. https:// doi.org/10.1046/j.1365-2958.2001.02435.x.

88. Sonnleitner E, Abdou L, Haas D. 2009. Small RNA as global regulator of carbon catabolite repression in Pseudomonas aeruginosa. Proc Natl Acad Sci U S A 106:21866-21871. https://doi.org/10.1073/pnas.pnas.0910308106. 
89. Allison KR, Brynildsen MP, Collins JJ. 2011. Metabolite-enabled eradication of bacterial persisters by aminoglycosides. Nature 473:216-220. https://doi.org/10.1038/nature10069.

90. Su Y-B, Peng B, Li H, Cheng Z-X, Zhang T-T, Zhu J-X, Li D, Li M-Y, Ye J-Z, Du C-C, Zhang S, Zhao X-L, Yang M-J, Peng X-X. 2018. Pyruvate cycle increases aminoglycoside efficacy and provides respiratory energy in bacteria. Proc Natl Acad Sci U S A 115:E1578-E1587. https://doi.org/10 $.1073 /$ pnas. 1714645115 .

91. Nguyen D, Joshi-Datar A, Lepine F, Bauerle E, Olakanmi O, Beer K, McKay G, Siehnel R, Schafhauser J, Wang Y, Britigan BE, Singh PK. 2011. Active starvation responses mediate antibiotic tolerance in biofilms and nutrient-limited bacteria. Science 334:982-986. https://doi.org/10 $.1126 /$ science. 1211037 .

92. Gusarov I, Shatalin K, Starodubtseva M, Nudler E. 2009. Endogenous nitric oxide protects bacteria against a wide spectrum of antibiotics. Science 325:1380-1384. https://doi.org/10.1126/science.1175439.

93. Shatalin K, Shatalina E, Mironov A, Nudler E. 2011. H2S: a universal defense against antibiotics in bacteria. Science 334:986-990. https://doi .org/10.1126/science.1209855.

94. Lee HH, Molla MN, Cantor CR, Collins JJ. 2010. Bacterial charity work leads to population-wide resistance. Nature 467:82-85. https://doi.org/ 10.1038/nature09354.

95. Vilchèze $C$, Hartman $T$, Weinrick $B$, Jain P, Weisbrod TR, Leung LW, Freundlich JS, Jacobs WR. 2017. Enhanced respiration prevents drug tolerance and drug resistance in Mycobacterium tuberculosis. Proc Natl Acad Sci U S A 114:4495-4500. https://doi.org/10.1073/pnas.1704376114.

96. Kwong WK, Zheng H, Moran NA. 2017. Convergent evolution of a modified, acetate-driven TCA cycle in bacteria. Nat Microbiol 2:17067. https:// doi.org/10.1038/nmicrobiol.2017.67.

97. Smith EE, Buckley DG, Wu Z, Saenphimmachak C, Hoffman LR, D'Argenio DA, Miller SI, Ramsey BW, Speert DP, Moskowitz SM, Burns JL, Kaul R, Olson MV. 2006. Genetic adaptation by Pseudomonas aeruginosa to the airways of cystic fibrosis patients. Proc Natl Acad Sci U S A 103:8487-8492. https://doi.org/10.1073/pnas.0602138103.

98. Döring G. 2010. Prevention of Pseudomonas aeruginosa infection in cystic fibrosis patients. Int J Med Microbiol 300:573-577. https://doi.org/ 10.1016/j.ijmm.2010.08.010.

99. Döring G, Parameswaran IG, Murphy TF. 2011. Differential adaptation of microbial pathogens to airways of patients with cystic fibrosis and chronic obstructive pulmonary disease. FEMS Microbiol Rev 35:124-146. https://doi.org/10.1111/j.1574-6976.2010.00237.x.
100. Kong W, Chen L, Wang Y. 2012. Identification of genes involved in longterm survival in Pseudomonas aeruginosa PAO1. Afr J Microbiol Res 6:7579-7586.

101. Wang T, Sun W, Fan L, Hua C, Wu N, Fan S, Zhang J, Deng X, Yan J. 2021. An atlas of the binding specificities of transcription factors in Pseudomonas aeruginosa directs prediction of novel regulators in virulence. Elife 10:e61885. https://doi.org/10.7554/eLife.61885.

102. Grant CE, Bailey TL, Noble WS. 2011. FIMO: scanning for occurrences of a given motif. Bioinformatics 27:1017-1018. https://doi.org/10.1093/ bioinformatics/btr064.

103. Bartosik AA, Glabski K, Jecz P, Lasocki K, Mikosa M, Plochocka D, Thomas CM, Jagura-Burdzy G. 2014. Dissection of the region of Pseudomonas aeruginosa ParA that is important for dimerization and interactions with its partner ParB. Microbiology (Reading) 160:2406-2420. https://doi.org/ 10.1099/mic.0.081216-0.

104. Sambrook J, Fritsch EF, Maniatis T. 1989. Molecular cloning: a laboratory manual, 2nd ed. Cold Spring Harbor Laboratory, Cold Spring Harbor, NY.

105. Irani VR, Rowe JJ. 1997. Enhancement of transformation in Pseudomonas aeruginosa PAO1 by $\mathrm{Mg}^{2+}$ and heat. Biotechniques 22:54-56. https://doi .org/10.2144/97221bm09.

106. Lasocki K, Bartosik AA, Mierzejewska J, Thomas CM, Jagura-Burdzy G. 2007. Deletion of the parA (soj) homologue in Pseudomonas aeruginosa causes ParB instability and affects growth rate, chromosome segregation, and motility. J Bacteriol 189:5762-5772. https://doi.org/10.1128/JB .00371-07.

107. El-Sayed AK, Hothersall J, Thomas CM. 2001. Quorum-sensing-dependent regulation of biosynthesis of the polyketide antibiotic mupirocin in Pseudomonas fluorescens NCIMB 10586. Microbiology (Reading) 147:2127-2139. https://doi.org/10.1099/00221287-147-8-2127.

108. Kawalek A, Bartosik AA, Glabski K, Jagura-Burdzy G. 2018. Pseudomonas aeruginosa partitioning protein ParB acts as a nucleoid-associated protein binding to multiple copies of a parS-related motif. Nucleic Acids Res 46:4592-4606. https://doi.org/10.1093/nar/gky257.

109. Kawalek A, Glabski K, Bartosik AA, Fogtman A, Jagura-Burdzy G. 2017. Increased ParB level affects expression of stress response, adaptation and virulence operons and potentiates repression of promoters adjacent to the high affinity binding sites parS3 and parS4 in Pseudomonas aeruginosa. PLoS One 12:e0181726. https://doi.org/10.1371/journal .pone.0181726 